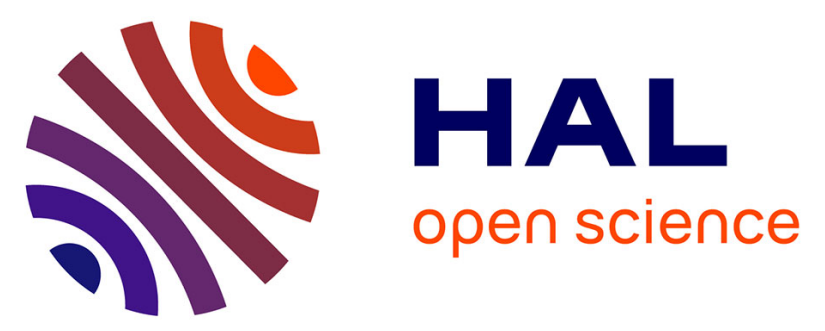

\title{
Probing Multiscale Structure of Mineral and Nanoporous Kerogen Phase in Organic-Rich Source and Neutron Scattering
}

\author{
Gaël J Cherfallot, Pierre E Levitz, Pauline Michel, Eric Kohler, Jacques
}

Jestin, Loïc Barré

\section{To cite this version:}

Gaël J Cherfallot, Pierre E Levitz, Pauline Michel, Eric Kohler, Jacques Jestin, et al.. Probing Multiscale Structure of Mineral and Nanoporous Kerogen Phase in Organic-Rich Source and Neutron Scattering. Sustainable Energy \& Fuels, 2020, 34 (8), pp.9339-9354. 10.1021/acs.energyfuels.0c01146 . hal-02959220

\section{HAL Id: hal-02959220 \\ https://hal-ifp.archives-ouvertes.fr/hal-02959220}

Submitted on 6 Oct 2020

HAL is a multi-disciplinary open access archive for the deposit and dissemination of scientific research documents, whether they are published or not. The documents may come from teaching and research institutions in France or abroad, or from public or private research centers.
L'archive ouverte pluridisciplinaire HAL, est destinée au dépôt et à la diffusion de documents scientifiques de niveau recherche, publiés ou non, émanant des établissements d'enseignement et de recherche français ou étrangers, des laboratoires publics ou privés. 


\section{and Neutron Scattering}

5 Gä̈l J. Cherfallot ${ }^{\dagger *}$, Pierre E. Levitz ${ }^{\dagger}$, Pauline Michel ${ }^{+}$, Eric Kohler ${ }^{*}$, Jacques Jestin ${ }^{\square}$ and Lö̈c

6 Barré $\dot{t}^{*}$

$7 \quad$ †Sorbonne Université, CNRS, UMR 8234, Physicochimie des Electrolytes et Nanosystèmes

8 Interfaciaux, 4 place Jussieu, F-75252 Paris, France

$9{ }^{\ddagger}$ IFP Energies Nouvelles, 1 et 4 avenue du Bois-Préau, 92852 Rueil-Malmaison, France

$10 \square$ Laboratoire Léon Brillouin, UMR 12, CEA Saclay, 91191 Gif-sur-Yvette cedex, France

$11 *$ Corresponding authors - Email gael.cherfallot@ifpen.fr , loic.barre@,ifpen.fr

12 ABSTRACT

13 Source rocks are expected to become increasingly important in the upcoming years for oil and gas

14 production as well as for the storage of greenhouse gases. These rocks are bedded and heterogeneous

15 media, composed of minerals, kerogen and pore space. One of the most challenging issue is to better 
16 define the pore space, including pore size distribution, pore volume fraction, pore connectivity and

17 pore affinity for various fluids. The aim of this study is to achieve such relevant parameters using X-

18 ray and neutron scattering techniques complementarity. Rocks thin blades cut normal to bedding plane

19 preserve sample integrity and allow their measurements on both techniques. 2D scattering patterns

20 show anisotropy, due to preferential orientation of lamellar minerals, which allows us to assess an

21 order parameter. This parameter is a valuable tool for mechanical and transport properties. A model

22 based on a three-phase system (minerals, kerogen and pores) is developed through the study of

23 scattering length density of each component within both radiations. The model allows us to fit both X-

24 ray and neutrons 1D data using the same model parameters. This later is then considered as selective.

25 It allows us to extract the kerogen mass density, the kerogen pore size distribution and its associated

26 volume fraction, and the chemical nature of kerogen pore content. This methodology has been applied

27 to a series of five source rocks of increasing maturities, from Barnett Shale Play and Montney-Doig

28 formations. Mature samples show a kerogen density of $\sim 1.6 \mathrm{~g} . \mathrm{cm}^{-3}$, a pore radius distribution centered

29 on $0.5-0.7 \mathrm{~nm}$ accounting for a pore volume fraction of $\sim 0.01-0.04$. These kerogen nanopores are

30 filled by light condensed hydrocarbons. However, the overmature kerogen exhibit a mass density of

$311.74 \mathrm{~g} . \mathrm{cm}^{-3}$, an additional pore radius distribution centered around $3.5 \mathrm{~nm}$ with a pore volume fraction

32 of 0.002 and an empty pore space. All these parameters are in agreement with Rock-Eval pyrolysiss

33 measurements and literature data on similar source rocks. These results pointed out that the three-

34 phase model associated with X-ray and neutron complementarity could be applied to in-situ studies.

\section{1. INTRODUCTION}

36 Source rocks formations are one of the most widespread reservoir on earth ${ }^{1}$ and display a high

37 potential of storage capacity. ${ }^{2}$ Since recent years, gas and oil coming from organic-rich source rocks

38 systems, also known as shale gas, present an increasing interest in North American and Asian 
39 countries. $^{3-4}$ In the next decade, shale gas production will reach almost a fifth of the world natural gas

40 production. ${ }^{4}$ Thus, such geological system is expected to be intensively exploited in the upcoming

41 years. $^{5}$ The source rocks are reported in the literature as a heterogeneous ${ }^{6}$ and anisotropic media ${ }^{7-10}$.

42 Shale gas are complex systems composed of several types of minerals (i.e. silicates, phyllosilicates,

43 tectosilicates, carbonates and iron sulfide) combined with organic matter (i.e. kerogen, bitumen and

44 pyrobitumen). ${ }^{11}$ The rock anisotropy observed within bedding structures suggests that a preferential

45 orientation condition the fluid flows through the system. ${ }^{12}$ The porous media are contained by both,

46 organic or inorganic phases with macropores $(>50 \mathrm{~nm})$ and mesopores (from 50nm to $2 \mathrm{~nm}$ ) mainly

47 located in minerals, and micropores $(<2 \mathrm{~nm})^{13}$ mostly encountered in the organic phases ${ }^{14-15}$ or in the

48 interlayer space of clay minerals. Fluids in pore space, such as gas and oil, are released by the organic

49 phase during the burial process. ${ }^{16}$ As it is also well known, this material has a low permeability (in the

50 range of $\mathrm{nD}),{ }^{17}$ low porosity and high retention capacity through physisorption mechanism ${ }^{18-19}$ which

51 may vary depending on the rocks micropores content. Currently, a scientific interest on source rocks

52 transport and storage properties led to an investigation on rock porosity. ${ }^{8,20-25}$ Studies are focusing on

53 the improvement of nanoporous media understanding through the assessment of total porosity, ${ }^{23,26-32}$

54 open versus closed pores content, ${ }^{10,33}$ pore size distribution, ${ }^{10,14,15,17,20-23,27,28,34-39}$ their

55 connectivity ${ }^{8,10,21,28,34}$ and the porous network tortuosity. ${ }^{34,40}$ Accordingly, several analytical methods

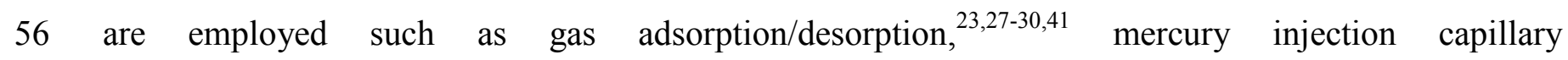

57 pressure, ${ }^{17,21,25,28,36,42}$ NMR relaxometry, ${ }^{43,44,45}$ NMR cryoporosimetry, ${ }^{46}$ multifrequency and

58 multidimensional $\mathrm{NMR}^{47}$ and Small-Angle Neutron Scattering (SANS). ${ }^{6,15,20,23,27,28,34,35,39,48}$

59 SANS is used to bring details on the source rocks total porosity ${ }^{28,38}$ and to determine their pore size

60 distribution (PSD). ${ }^{10,23,28,38}$ A dedicated workflow was developed from a few decades through the

61 acquisition of SANS data. ${ }^{6,15,20,23,27,28,34,35,39,48}$ Classically, source rocks are described as a two-phase 
62 system, depending on the matrix (i.e. mineral and organic matter) and the pore space. Then, scattering

63 data are modeled by the polydisperse spherical pore (PDSP) model weighted by a term of contrast

64 between the sample matrix and the pores space..$^{20,27,28,34,35}$

65 The model describes the scattering intensity $I(Q)$ of diluted spherical pores of radius $R$ (Equation 1 )

66 as a function of the volume fraction, $\phi=\int_{R \min }^{R \max } N(R) \cdot V(R) d(R)$, of polydisperse spheres, the

67 form factor $P(Q, R)$ of spheres, and their volume, $V(R)$. Such model depend on the squared Scattering

68 Length Density (SLD) $\rho$ difference of the considered phases, such as the matrix or the pore space, and

69 can be expressed as follows:

70

$$
I(Q)=\left(\rho_{\text {matrix }}-\rho_{\text {pores }}\right)^{2} \int_{R_{\text {min }}}^{R_{\text {max }}} N(R) \cdot V^{2}(R) \cdot P(Q, R) d(R)
$$

72 From these modeling a PSD is determined as well as the sample total porosity $\phi$. Small-angle

73 scattering is one of the rare technique which probe the total pore space. Both SAXS and SANS

74 techniques, are based on the same principle, it is then possible in theory to obtain similar results ${ }^{48}$.

75 However, small-angle X-ray scattering on source rocks is less investigated ${ }^{49,50}$ than SANS owing to

76 the presence of pyrite, with a different SLD than other minerals, introducing a supplementary phase.

77 Beam types as neutron or X-ray have a different interaction through the material which can be

78 exploited as a complementary. Indeed, the different X-ray and neutron contrast are expected to better

79 define the chemical nature of fluids in pore space.

80 Herein, this work is focused on the neutron and X-ray scattering profiles similarities and 81 complementarities. The aim is first to provide details on the minerals orientation, the kerogen mass

82 density, pore size contained in the kerogen phase and their associated volume fraction, and then to 83 assess the nature (gas or oil) of fluids in place. A multi-technical approach through the comparison of 
84 X-Ray diffraction, Rock-Eval pyrolysis, Headspace gas chromatography, Field-Emission Scanning

85 Electron Microscopy and small-angle scattering techniques, is expected to bring rocks structural

86 information. For that, five source rock samples are selected based on their petrological and

87 geochemical properties to form a continuous sequence of organic matter maturity. Their X-ray and

88 neutron scattering intensities are then compared in order to get new information on (i) minerals

89 orientation relatively to the bedding plane, (ii) the maturity of kerogen, (iii) the pore size distribution

90 and the occupancy of pores in respect to gas or hydrocarbon phase.

91

92 2. MATERIALS AND METHODS

$93 \quad$ 2.1. Source rocks.

94 Source rocks chosen and used in this study were provided by IFPEN and were collected from two 95 geological North-American Formations as part of research projects dedicated to unconventional oil 96 and gas reservoirs (GASH European program (2009-2012) and MGH IFPEN internal research 97 program). Four samples named as BSP-2, BSP-3, BSP-4 and BSP-5 come from the Mesquite 1 well of 98 the Barnett Shale Play (BSP) (Texas - United States). The BSP samples were deposited in a foreland 99 basin in the Fort Worth Basin. These rocks are fine grained laminar silicate-rich and organic-rich 100 source rocks. The last sample MT-1 originates from the Cypress field (well C-30-1 / 94-b-15) of the 101 Montney-Doig Formation (MT) (Alberta and British Columbia - Canada). This sample was deposited 102 during sediment accumulations in a foreland basin. It is a laminated coarse grained silicate-rich and 103 organic-rich rocks. In the Table 1, general information about the sample geological formation and the 104 depth at which they were collected, are listed. 


\subsection{Sample preparation.}

106 For Rock-Eval pyrolysis and X-Ray Diffraction (XRD) measurements, samples were crushed into <

$10750 \mu \mathrm{m}$ powders. HeadSpace Gas Chromatography (HS-GC) analysis was performed on rock sections

108 cut parallel and also cut normal to bedding. These sections were shaped into parallelepiped subsample

109 of about $1 \times 2 \times 0.2 \mathrm{~cm}$. Field Emission Scanning Electron Microscopy (FESEM) observations and

110 scattering measurements were made on rock thin blade sections cut normal to bedding. A schematic

111 summary for sample preparation according to the technique used is illustrated Figure 1.

112 Source rocks are a heterogeneous systems where a representative volume is difficult to assess. In

113 addition, the comparison between Small-Angle Neutron Scattering (SANS) and Small-Angle X-ray

114 Scattering (SAXS) measurements requires to be performed on a similar probed volume as both

115 techniques have different beam sizes, classically $0.5 \times 0.5 \mathrm{~mm}$ for SAXS and $5 \times 5 \mathrm{~mm}$ for SANS.

116 Sample thickness optimization is also important as optical path is related both to the sample

117 transmission, different for each radiation, and to multi scattering issues. ${ }^{22,33,35,38,39,51}$ In the chosen

118 conditions (see below), transmission is high for SANS about $90 \%$, and low for SAXS, around $10 \%$.

119 From these considerations and prior to this study, the sample thickness and the probed volume 120 homogeneity were assessed on a sample, called MT-2, with a low Total Organic Carbon (TOC) 121 content $(1.4 \% \mathrm{wt})$, extracted from the well 0/14-32-073-08W6 of the Montney-Doig formation at a 122 depth of 2070 meters. This well is located at $270 \mathrm{Km}$ South-East of MT-1 sample. MT-2 was chosen 123 to evaluate the effect of mineral variability on scattering intensity, as it have a low TOC content. The 124 influence of sample thickness on SAXS data were analyzed to determine the occurrence of multiple 125 scattering effects. SAXS measurements were conducted on MT-2 normal cut to bedding thin blade 126 sections within a thickness of 100,140 and $210 \mu \mathrm{m}$. Scattering intensities were normalized to the 127 sample thickness and transmission. Results (supplementary information) show that intensities in 
128 absolute units are about the same according to three different sample thickness suggesting (i) no 129 multiple scattering in this $Q$ range and (ii) measurements are performed in an almost homogeneous 130 probed volume. The multiple scattering effect was only checked on SAXS data assuming, as suggested 131 by Anovitz and Cole (2015), the fact that if the transmission is greater than $90 \%$, the multiple 132 scattering effects remains small.

133 To complete our view on probed volume homogeneity, SAXS measurements were performed on 9 134 and 5 random positions on the $140 \mu \mathrm{m}$ thick MT-2 sample with a 200 x $200 \mu \mathrm{m}$ beam size. Results 135 were decomposed as the sum of power law trends as $A \cdot Q^{-\alpha}$. Then, the $A$ or $\alpha$ parameters were used to 136 define the variability of each parameter. The $\alpha$ parameter vary within $1 \%$ whereas the prefactor vary 137 within less than five percent. The latter is thought to be correlated with concentration, size and contrast 138 of various scatterers. We conclude from the low dispersion of $A$ and $\alpha$ parameters that with this beam 139 size, the sample phase distribution is almost constant. Moreover, the SAXS intensities measured on 9 140 or 5 random positions were averaged to get a more representative volume to be compared with neutron 141 measurements.

142 As this study is partly focused on the analysis of source rock anisotropy, the samples were cut 143 normal to bedding plane to maximize the occurrence of lamination, as shown in Figure 1. Rocks thin 144 blade sections with a maximum thickness of $200 \mu \mathrm{m}$ were prepared and stuck to pierced quartz blades 145 with a pinhole of $5.5 \mathrm{~mm}$ diameter. This diameter allows to map and to average several SAXS 146 measurements in order to probe about the same volume as SANS ; in this way, the comparison of X147 ray and neutron scattering intensities are meaningful. Concerning the homogeneous probed volume of 148 samples used in this study, SAXS measurements were performed on five random location for each 149 sample. Obtained scattering intensities were checked and compared to the mean intensity. It reveals no 
150 significant variation allowing us to consider that the probed volume display a constant phase 151 distribution.

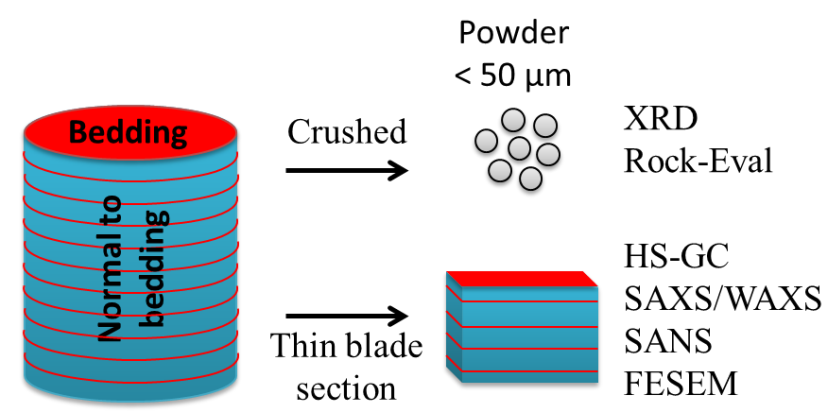

$152 \quad$ Figure 1. Schematic representation of sample preparation with in blue normal to bedding plane and in red the bedding.

154

155

156

157

158

159

160

\subsection{Rock-Eval ${ }^{\circledR} 6$ pyrolysis.}

Geochemical data on organic matter were obtained by Rock-Eval pyrolysis according to the Shale Play method. ${ }^{31,52}$ This technique is used to define the TOC content, the organic matter type and the maturity through HI vs Tmax diagram, as shown in Table 1 and in Figure 2. 11,23,24,26,28-31,34,35,53-55 Analysis was performed on $60 \mathrm{mg}$ of dry bulk-rock powder and standard deviation was assessed through the repeatability of five measurements of each sample.

Samples have a TOC content ranging from $4.5 \% \mathrm{wt}$ (BSP-2 and BSP-3) up to $9.0 \% \mathrm{wt}$ (BSP-4). The

Figure 2 illustrates sample measurements, all of them are consistent with a kerogen of type II. $^{56,57}$ These samples follow an increasing depositional depth from BSP-2 (1126 m) to MT-1 (2561 m). BSP samples are mature, as $\mathrm{HI}$ range from 146 to $174 \mathrm{mg} \mathrm{HC} / \mathrm{g}$ TOC and Tmax is close to $445^{\circ} \mathrm{C}$. They are in the oil window and the MT-1 sample reach the dry gas window which means that it is overmature $\left(\mathrm{HI}=17 \mathrm{mg} \mathrm{HC} / \mathrm{g}\right.$ TOC and $\left.\mathrm{Tmax}=598^{\circ} \mathrm{C}\right)$. As shown by Craddock and coworkers 
169 (2018), ${ }^{11}$ there is a strong correlation between the depositional depth and the maturity of the sample.

170 An increase of the maturity along the depth is then expected.

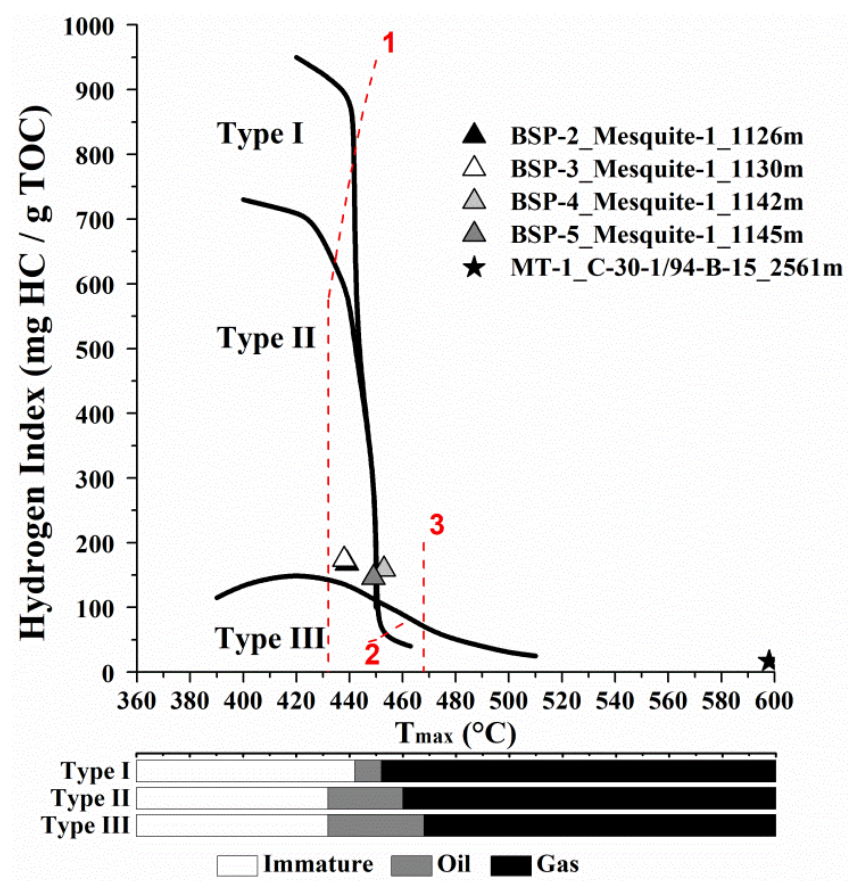

171 Figure 2. HI as a function of Tmax diagram with delineations 1, 2 and 3 defining the limit of the oil-

172 gas window for kerogen of type I, II and III. ${ }^{54}$ BSP samples are represented by triangles and MT-1 is

symbolized by a star.

Table 1. Rock-Eval pyrolysis data obtained within the Shale Play method on the five source rock samples. (a) Data expressed in mg HC / g rock.

\begin{tabular}{|c|c|c|c|c|c|c|c|c|c|c|}
\hline Formation & Reference & Well & $\begin{array}{c}\text { Depth } \\
\text { m }\end{array}$ & Maturity & $\begin{array}{l}\text { Sh0 } \\
\text { (a) }\end{array}$ & $\begin{array}{l}\text { Sh1 } \\
\text { (a) }\end{array}$ & $\begin{array}{l}\text { Sh2 } \\
\text { (a) }\end{array}$ & $\begin{array}{l}\text { Tmax } \\
\left({ }^{\circ} \mathrm{C}\right)\end{array}$ & $\begin{array}{c}\text { HI } \\
\mathrm{mg} \mathrm{HC} / \mathrm{g} \text { TOC }\end{array}$ & $\begin{array}{l}\text { TOC } \\
\text { wt \% }\end{array}$ \\
\hline \multirow{4}{*}{$\begin{array}{l}\text { Barnett } \\
\text { Shale Play }\end{array}$} & BSP-2 & $\begin{array}{c}\text { Mesquite } \\
1\end{array}$ & 1126.7 & Mature & 2.36 & 2.7 & 7.5 & 439 & 168 & 4.5 \\
\hline & BSP-3 & $\begin{array}{c}\text { Mesquite } \\
1\end{array}$ & 1130.5 & Mature & 2.55 & 3.5 & 7.8 & 438 & 174 & 4.5 \\
\hline & BSP-4 & $\begin{array}{c}\text { Mesquite } \\
1\end{array}$ & 1142.4 & Mature & 2.09 & 3.0 & 14.5 & 453 & 159 & 9.0 \\
\hline & BSP-5 & $\begin{array}{c}\text { Mesquite } \\
1\end{array}$ & 1145.4 & Mature & 1.57 & 2.5 & 11.9 & 449 & 146 & 8.1 \\
\hline
\end{tabular}




\begin{tabular}{lllllllllll}
$\begin{array}{c}\text { Montney- } \\
\text { Doig }\end{array}$ & MT-1 & $\begin{array}{c}\text { C-30-1/ } \\
94-\mathrm{b}-15\end{array}$ & 2561.8 & Overmature & 0.09 & 0.3 & 0.8 & 598 & 17 & 4.8 \\
\hline & $\begin{array}{l}\text { Standard } \\
\text { deviation }\end{array}$ & & \pm 0.06 & \pm 0.02 & \pm 0.04 & \pm 0.6 & & \pm 0.6 & \pm 0.01 \\
\hline
\end{tabular}

\subsection{HeadSpace Gas Chromatography.}

177 To obtain detailed information on Sh0 peak and on the free hydrocarbon composition, samples are 178 characterized by HS-GC. This thermodesorption method is based on a partial pressure equilibrium 179 between the fluid in the source rocks and the vapor outside the rock generated at a given temperature.

180 For that purpose, this technique is only used as qualitative tool in this study on thin rock section 181 samples whom preparations and representations are described in section 2.2. HS-GC measurements 182 were performed on an Agilent 7890B-GC chromatograph equipped with a Headspace Sampler Agilent 183 7697A. Samples were put into a $15 \mathrm{~mL}$ vial at $80^{\circ} \mathrm{C}$ between 5 minutes to 7 days. Then, a volume of

$18415 \mu \mathrm{L}$ is taken from the vapor and injected into the chromatograph. Data on the composition between

$185 \mathrm{C}_{1}$ and $\mathrm{C}_{11}$ were acquired using a chromatographic column consisting in a fused-silica capillary coated 186 with $\mathrm{Al}_{2} \mathrm{O}_{3}$ of about 30 meters with a flow rate of $1.6 .10^{-2} \mathrm{~mL} \cdot \mathrm{s}^{-1}$, an input temperature of $160^{\circ} \mathrm{C}$ and 187 output temperature of $210^{\circ} \mathrm{C}$. Data were normalized to the sample weight and compared to a standard 188 (Supelco $\left.^{\mathcal{O}} \mathrm{n}^{\circ} 21823895\right)$ for the peak indexation.

189 The distribution of $n$-alkane obtained by HS-GC as a function of heating time and retention time is 190 represented in Figure 3 for the BSP-4 sample cut normal to bedding plan. Based on this sample study,

191 light compounds such as $\mathrm{C}_{1}$ to $\mathrm{C}_{8}$ are shown to be preserved during the sample preparation. Results 192 from chromatographs reveal that, at $\mathrm{t}=4 \mathrm{~min}$ to $10 \mathrm{~min}$, the main contribution to hydrocarbon 193 composition are ascribed to light compounds from $C_{1}$ to $C_{5}$. Over several heating times, from 5 194 minutes to 7 days, the gas distribution remains unchanged with an increasing pressure. This reveals an 
uncompleted gas release as no partial pressure equilibrium between the vapor outside and the fluid in

196 the rock is reached. One may explain it by the rock composition which contains silicates with $\mathrm{Si}-\mathrm{OH}$

197 groups and also illite and feldspar with $\mathrm{Al}_{2} \mathrm{O}_{3}$ groups which act as retention sites. Such functional 198 groups are classically used in chromatographic fused-silica column as adsorption surfaces. Thus, a 199 chromatographic effect can be observed in the rock as adsorption/desorption can occur on functional 200 groups leading to an uncomplete desorption within the heating time used. Anyway, this suggests that 201 the diffusion through the sample is low which is consistent with a low permeability as source rocks 202 porous media display connected and disconnected pore spaces. ${ }^{7,27,34,55,58-61}$ Measurements on parallel 203 and normal cut to bedding plane were also performed, for heating times ranging from 5 to 480 204 minutes. Results, shown in supplementary information, reveal that desorption rate, at a given time, is 205 always lower for parallel cuts to bedding plane than for normal ones.

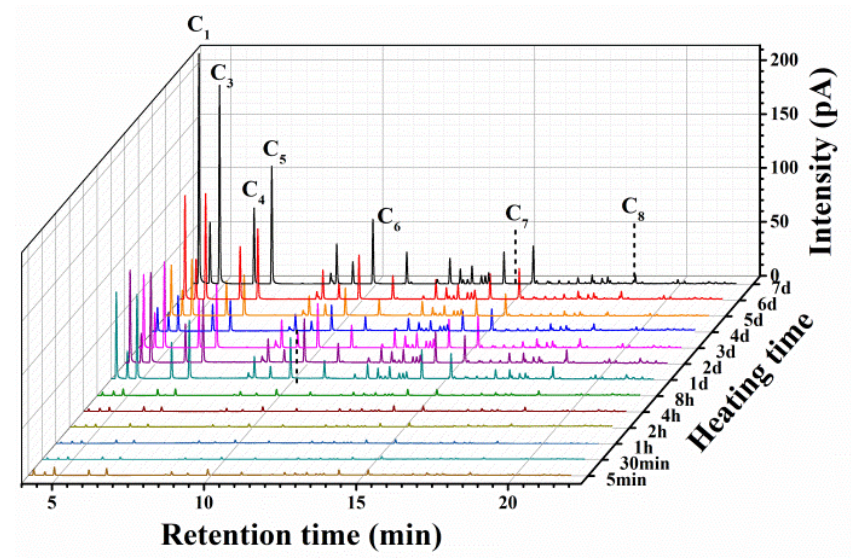

Figure 3. Chromatographs of the BSP-4 sample, cut normal to bedding plan, over several heating times, from 5 minutes to 7 days, in an oven at $80^{\circ} \mathrm{C}$.

\subsection{XRD Measurements.}

209 The mineral composition was determined using a PANalytical X'pert Pro diffractometer using a 210 detector X'celerator and equipped with a Copper X-ray tube $(\mathrm{Cu}-\mathrm{K} \alpha=1.5418 \AA)$. Data were acquired 211 on disoriented powder samples and according to the following analytical conditions: $45 \mathrm{kV}, 40 \mathrm{~mA}$, 
212 angular sector from 2 to $80^{\circ} 2 \theta$. Then, minerals quantification in weight percent, was achieved by

213 Rietveld ${ }^{62}$ analysis using the software X'pert High Score Plus.

214 The mineralogical composition of the five studied source rocks is given in Table 2. The mineral

215 content in weight percent, is then converted in volume percent for the SLD calculation. The major

216 mineral phase encountered in BSP and MT samples are silicates lato sensu with quartz as main

217 mineral (> $30 \mathrm{vol} \%$ ) followed by illite (4 to $20 \mathrm{vol} \%$ ) and muscovite (15 to $28 \mathrm{vol} \%$ ). The second

218 contribution to mineral phase is carbonate minerals with 4 to 27 vol $\%$. Then, pyrite content varies

219 from almost 1 vol \% to 2.5 vol \%. This mineral composition agrees with other studies on the same 220 geological formations. ${ }^{56,63}$

222 Table 2. Normalized mineral compositions of BSP and MT samples converted in volume percent (vol \%) using the mineral density (a) defined in the database www.webmineral.com.

\begin{tabular}{|c|c|c|c|c|c|c|}
\hline Phase & $\begin{array}{l}\text { Density } \\
\left(\mathrm{g} / \mathrm{cm}^{3}\right)\end{array}$ & $\begin{array}{l}\text { BSP-2 } \\
(\operatorname{vol} \%)\end{array}$ & $\begin{array}{l}\text { BSP-3 } \\
(\text { vol \%) }\end{array}$ & $\begin{array}{l}\text { BSP-4 } \\
\text { (vol \%) }\end{array}$ & $\begin{array}{l}\text { BSP-5 } \\
(\mathrm{vol} \%)\end{array}$ & $\begin{array}{l}\text { MT-1 } \\
\text { (vol \%) }\end{array}$ \\
\hline Quartz & $2.65^{(\mathrm{a})}$ & 41.9 & 41.7 & 30.1 & 31.6 & 36.4 \\
\hline Albite & $2.62^{(\mathrm{a})}$ & 12.0 & 9.0 & 15.4 & 12.5 & 6.5 \\
\hline Muscovite & $2.90^{(\mathrm{a})}$ & 15.6 & 13.7 & 28.0 & 22.5 & 17.9 \\
\hline Illite & $2.75^{(\mathrm{a})}$ & 12.4 & 14.8 & 19.8 & 12.8 & 4.1 \\
\hline Calcite & $2.71^{(\mathrm{a})}$ & 8.5 & 12.7 & - & 17.4 & 8.6 \\
\hline Dolomite & $2.87^{(\mathrm{a})}$ & 8.5 & 7.1 & - & 1.4 & 18.3 \\
\hline Apatite & $3.19^{(a)}$ & - & - & 4.3 & - & - \\
\hline Pyrite & $4.93^{(\mathrm{a})}$ & 1.1 & 0.9 & 2.3 & 1.8 & 2.5 \\
\hline
\end{tabular}


Visual information on phase distribution is required to determine the occurrence of scattering

227 contrast. For this reason, FESEM was used in order to acquire images on rock structures and organo-

228 mineral phases distribution at a large scale (from hundreds of microns to dozens of nanometers).

229 Observations on normal cut to bedding plane samples were made at $12 \mathrm{~nm} / \mathrm{pxl}$. Experiments were

230 carried out on a FESEM Nova NanoSEM 450 on cryogenic argon ion polished sample. Images were

231 acquired with a working distance ranging from 5.2 to $5.5 \mathrm{~mm}$ and a probe current of $2.5 \mathrm{KV}$.

232 The FESEM images of rock structures and phase distributions are shown in Figure 4. Four Fields of

233 View (FOV), from $51 \mu \mathrm{m}$ down to $2,5 \mu \mathrm{m}$, were observed to account for the orientation of micas and

234 clay minerals, the pores in mineral matrix and the pore within the kerogen phase. Five types of 235 structure are identified:

236 - Pyrite, crystallizing in a cubic system as framboidal and cubic shapes, have a high absorption 237 coefficient leading to white objects on FESEM images,

238 - Dark grey aggregates account for the organic matter as this material is composed of light 239 elements with a low absorption coefficient,

240 - Dark grey level is assigned to pores in both organic and inorganic phases,

241 - Subangular minerals, with a light grey level between the organic matter and pyrite minerals, are 242 attributed to quartz,

243 - Feldspars, with the same grey level as quartz, exhibits an angular shape allowing their 244 identifications,

245 - Carbonaceous minerals, similar to feldspars in shape, have a higher density. These minerals have 246 also an angular shape but some intra-granular pores can be encountered owing to liquid 247 dissolution phenomenon which is used for the identification,

248 - Macroscopic elongated minerals, larger than two microns, are micas, 
- Fine elongated minerals, lower than two microns, are consistent with clayey mineral such as

$250 \quad$ illite.

251 Figure 4(a), Figure 4(b) and Figure 4(c) display macroscopic observations (FOV $=51 \mu \mathrm{m}$ and $25213 \mu \mathrm{m}$ ) on the BSP-4 (a and b) and BSP-5 (c) samples depicting a preferential orientation of micas 253 and clay minerals. Such features exist at a lower scale (FOV $=2,5 \mu \mathrm{m})$ as well as in Figure 4(d)

254 coming from BSP-5 sample. Moreover, Figure 4(c) highlights that isolated porosity exists in the 255 minerals and is mostly widespread in carbonaceous phases. Comparing Figure 4(c) and Figure 4(d), 256 shows that pores in minerals are mainly macropores with a lower amount of mesoporosity while 257 mesopores are the major porosity in organic matter.

258
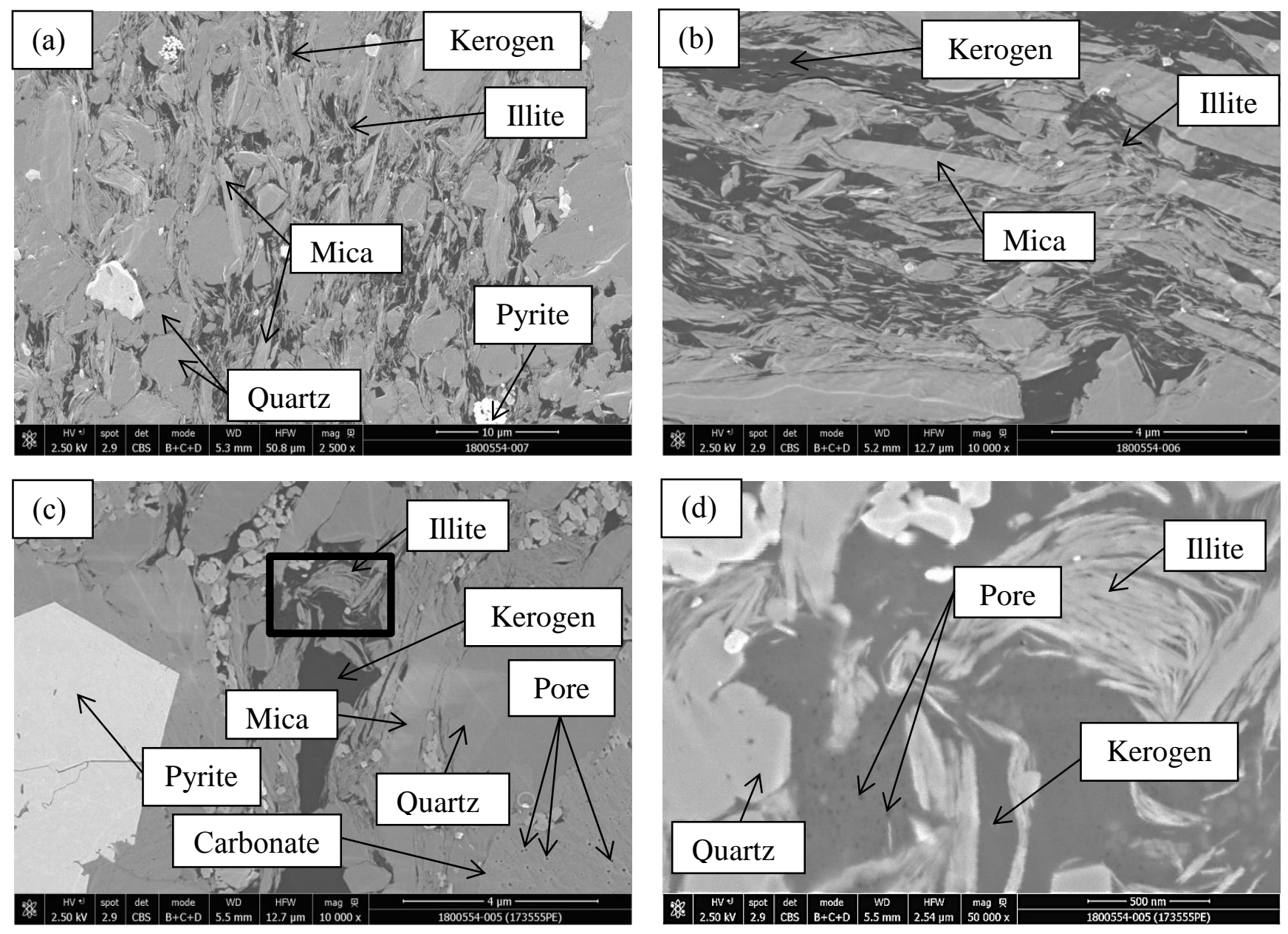
Figure 4. FESEM observations performed on BSP-4 ( $a$ and $b$ ) and BSP-5 sample ( $c$ and $d)$ with

260 different fields of view, (a) $51 \mu \mathrm{m}$, (b) and (c) $13 \mu \mathrm{m}$ and (d) 2,5 $\mu \mathrm{m}$, to depict the phase distribution. 


\subsection{Scattering experiments}

263 2.7.1. SAXS and WAXS measurements. SAXS instrument is equipped with a $\mathrm{Cu}$ rotating anode

264 (Rigaku MM07, at the wavelength of $\lambda=1.5418 \AA$ ) and a 2D detector (Rigaku). The sample to 265 detector distance is about $73.6 \mathrm{~cm}$ and allows the measurement of a scattering vector $Q$ ranging from $2660.03 \AA^{-1}$ up to $0.6 \AA^{-1}$. The instrument is also equipped with a WAXS 2D detector and enlarges the 267 studied area until $1.6 \AA^{-1}$. The experimental setup is illustrated Figure 5. The scattering vector $Q$ can 268 be seen as an inverse correlated length scale in the reciprocal space and is defined as $Q=4 \pi \cdot \sin \theta / \lambda$ 269 with $2 \theta$ being the scattering angle. In the case of source rocks, WAXS measurements allows the 270 identification of the 001 Bragg peaks of illite located at $d_{001}=2 \pi / Q=10.0 \AA$. SAXS/WAXS data 271 of each sample were corrected to their transmission, their thickness, the empty beam signal and 272 normalized to a lupolen standard. The scattering intensity obtained on WAXS data are rescaled to the 273 scattering intensity of SAXS data. Thus, the scattering intensity is expressed in absolute unit, $\mathrm{cm}^{-1}$, for 274 both techniques. The presence of a continuous and flat background on WAXS data at high $Q$ values 275 indicates the occurrence of a signal distributed over $4 \pi$ which doesn't depend on $Q$ vector. Two 276 phenomena can contribute to the background at high $Q$ values : (i) mineral in homogeneities at sub 277 nanometer length scale giving rise to scattering intensities with small $Q$ dependence, and (ii) 278 fluorescence, since the $C u$-K $\alpha$ energy $(8.04 \mathrm{KeV})$ and $F e ~ K$-edge energy $(7.11 \mathrm{KeV})$ are close and lead 279 to a constant scattering, independent of the $Q$ vector. As WAXS data allow to observe a very constant 280 background over high $Q$ values, this phenomenon is attributed to the fluorescence of the iron 281 contained in pyrite which needs to be subtracted, as shown in Figure 6(a). 


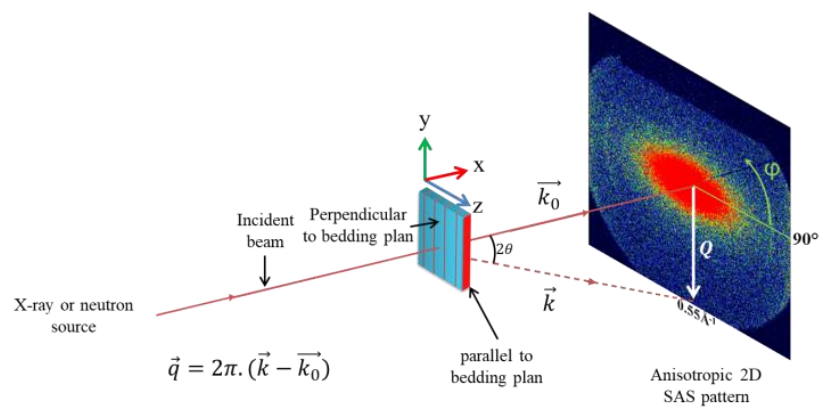

282 Figure 5. Schematic representation of SAXS/WAXS configuration with respect to the laboratory frame $(x, y, z)$.

284 2.7.2. SANS measurements. SANS experiments were carried out on the PA20 spectrometer at 285 Laboratoire Léon Brillouin (CEA/CNRS) at Saclay, France. Three different configurations ((i) $\lambda=3.8$ $286 \AA$ /sample-to-detector distance $(D)=1.1 \mathrm{~m}$, (ii) $\lambda=6 \AA / D=8 \mathrm{~m}$ and (iii) $\lambda=15 \AA / D=17.5 \mathrm{~m}$ ), gives a 287 total $Q$-range from $9 \cdot 1 \cdot 10^{-4} \AA^{-1}$ to $5 \cdot 1 \cdot 10^{-1} \AA^{-1}$. To be compared with SAXS/WAXS data, it is 288 mandatory to express the SANS intensity in absolute units. For that purpose, SANS measurements of 289 each sample were also corrected by their transmission, their thickness, the detector pixel efficiency 290 and normalized to the incident beam. Assuming that the almost flat background at high $Q$ values is 291 related to the incoherent scattering of the hydrogen contained in the sample, the mean intensity value 292 of the last $Q$ values $\left(0.45\right.$ to $\left.0.51 \AA^{-1}\right)$ was assessed and subtracted, as shown in Figure $6(b)$. The 293 validity of this assumption will be discussed in the result section. 

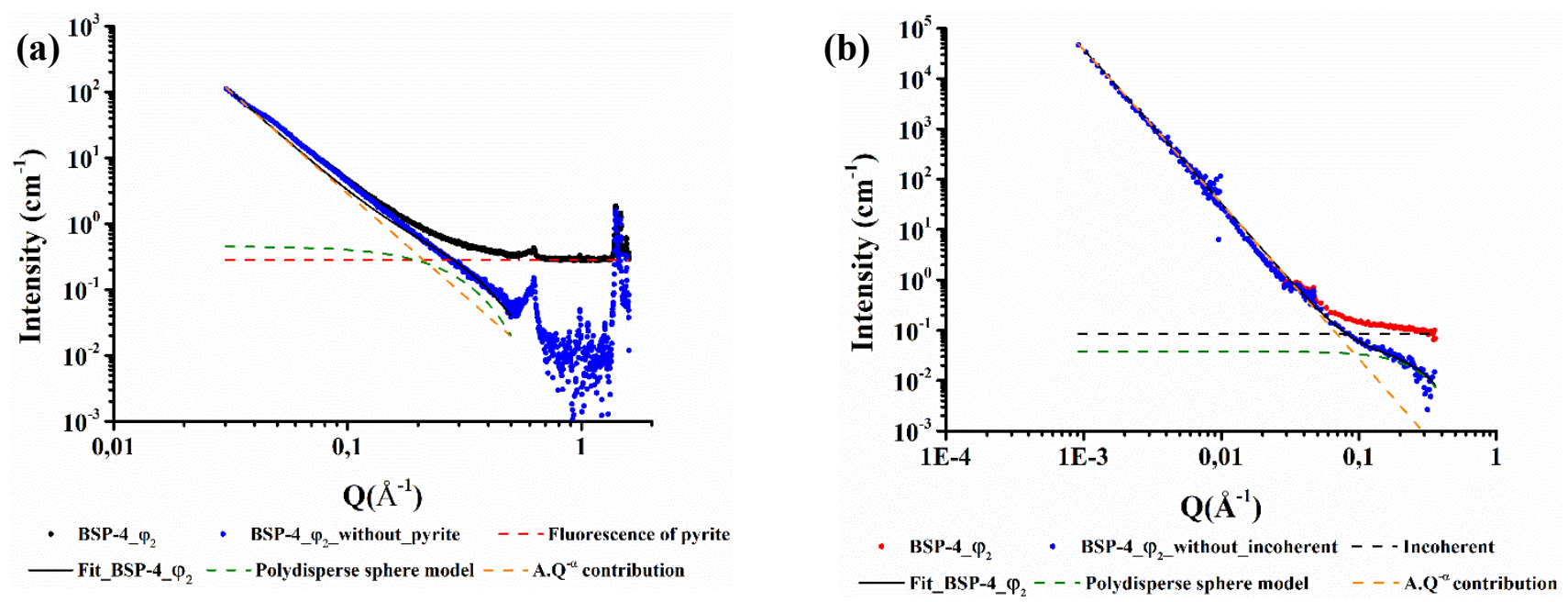

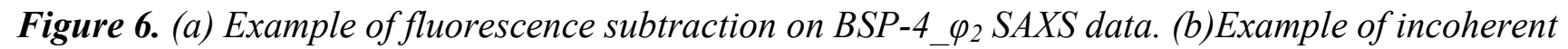
subtraction on BSP-4_ $\varphi_{2}$ SANS data. Both scattering profiles are displayed as a function of two contributions, log normal (dark green dash lines) and A. $Q^{-\alpha}$ (orange dash lines). scattering 2D anisotropic pattern, as shown in Figure 7. As defined earlier, studied source rocks are laminated rocks. It is then possible to measure a 2D scattering pattern being anisotropic. Consequently, radial average of 2D pattern was realized using two angular sectors as illustrated in Figure 7(a). The first sector $\varphi_{1}$ is defined by the angle $\varphi=90^{\circ}$ along the elongated part of the anisotropic pattern with an aperture angle of $\Delta \varphi=60^{\circ}$. The other one $\varphi_{2}$ is normal to the angle $\varphi_{1}$ as $\varphi_{1}+90^{\circ}$ and $\Delta \varphi=60^{\circ}$.

304 Obtained scattering curves, displayed in Figure 7(c), exhibit the scattering intensity as a function of the wave vector $Q$.

The anisotropic 2D scattering patterns suggest that in the system some scatterers are preferentially oriented along one direction. Thus, scattering patterns were also azimuthally averaged according to two distinct regions, as shown in Figure 7(b). The first one, $S_{l}$, is at low $Q$ values, $5.10^{-2}<Q<0.2 \AA^{-1}$, and the second region, $S_{2}$, is in high $Q$-region, $0.34<Q<0.5 \AA^{-1}$. From the 1D curve, illustrated in Figure $7(d)$, the variation of the scattering intensity is plotted as a function of the azimuthal angle $\varphi$ 311 from $0^{\circ}$ to $360^{\circ}$ with an aperture step angle of $5^{\circ}$. As particles are oriented, the scattering intensity 
312 gives information on the main orientation of particles and on the sample structure. The order

313 parameter $S$ - denoted sometimes the Herman's parameter - quantifies the material anisotropy and is

314 used frequently in nematic crystal and clays domains. ${ }^{64-67}$

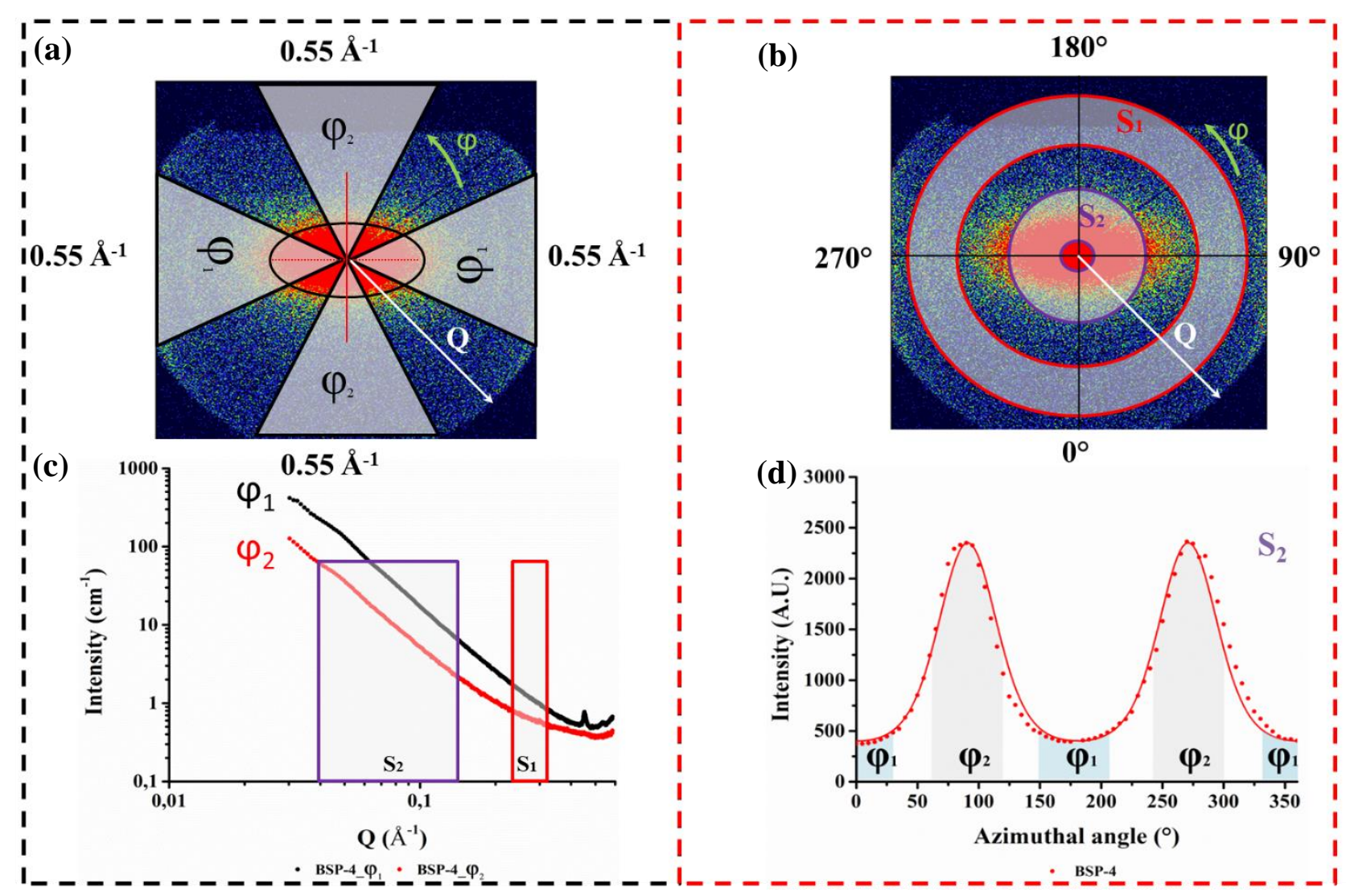

315

316

317

318 One popular way to fit anisotropic SAXS data is to use, for a small $Q$ range, the Maier-Saupe

319 function $^{68,69}$ defined as :

$$
f(\varphi)=A+B \cdot \exp \left(m \cdot \cos ^{2}\left((\varphi-\psi) *\left(\frac{\pi}{\mathbf{1 8 0}}\right)\right)\right)
$$


321 Where $A$ is the flat background, $B$ is a multiplier coefficient, $m$ accounts for the particle orientation, $322 \varphi$ is the azimuthal angle and $\psi$ is the maximum of intensity. Then, the Maier-Saupe data are 323 normalized to their area, to compare results obtained for each sample, according to :

$$
A=\int_{0}^{\pi} f(\theta) \cdot \sin (\theta) d \theta
$$

325 and

$$
f(\theta)_{n o r m}=\frac{f(\theta)}{2 \pi \cdot A}
$$

327 With $\theta$ the normal to the angle between the particle and the laboratory frame $z$ axis.

328 Afterward, the order parameter $S$ is expressed as the mean of a second-order Legendre polynomial :

$$
S=\left\langle\frac{3 \cdot \cos ^{2}(\theta)-1}{2}\right\rangle
$$

330 And integrated over the whole solid angle $\sin (\theta) . d \theta \cdot d \varphi$ :

$$
S=\int_{0}^{2 \pi} d \varphi \int_{0}^{\pi} f(\theta)_{n o r m} \cdot \frac{3 \cdot \cos ^{2}(\theta)-1}{2} \cdot \sin (\theta) d \theta
$$

332 The order parameter values range from 0 , isotropic media, to 1 , perfectly oriented particles as 333 columnar or smectitic crystal-liquid phases. ${ }^{66}$ 


\subsection{Frame of Scattering modeling}

337 Scattering intensities being related to the so called Scattering Length Densities (SLD) fluctuations, 338 we first examined what are SLD in source rocks for both neutron and X-ray and secondly how SLD 339 may be taken into account in intensities modeling.

\section{$340 \quad$ 3.1.1. Scattering Length Densities}

341 The SLD of a component or a phase is related to its elemental composition and to the type of

342 radiation used. For each component, SLD is calculated according to the formula: ${ }^{20,21,27,28,70}$

$$
\rho=\frac{1}{V} \sum_{i} n_{i} b_{i}
$$

344 Where $V$ is a volume representative of the component, $n_{i}$ the number of atoms of type $i$ contained in 345 the volume $V$ and $b_{i}$ the atomic scattering length. The latter are tabulated for neutrons in the NIST 346 Database (https://www.ncnr.nist.gov/resources/n-lengths/), whereas they are estimated for X-ray

347 according to $b_{i}=0.282 .10^{-12} Z_{i}(\mathrm{~cm})$ where $Z_{i}$ is the atomic number of atoms of type $i$. For a mixture of 348 components, the mean $\mathrm{SLD},\langle\rho\rangle$, for both radiation beam is established according to:

$$
\langle\rho\rangle=\sum_{j} \phi_{j} \rho_{j}
$$

350 With $\sum_{j} \phi_{j}=1, \phi_{j}$ the volume fraction of the component $j$ and $\rho_{j}$ the SLD of the component $j$.

351 From FESEM observations, three different phases are observed : mineral, kerogen and pores.

$352 \quad$ Minerals :

353 The SLD of the main minerals in our samples are reported on Table 3. 


\begin{tabular}{|c|c|c|c|c|}
\hline \multirow[b]{2}{*}{ Phase } & \multirow[b]{2}{*}{ Chemical formula $^{(a)}$} & \multirow{2}{*}{$\begin{array}{c}\text { Density }^{(\mathrm{a})} \\
\left(\mathrm{g} / \mathrm{cm}^{3}\right)\end{array}$} & \multicolumn{2}{|c|}{ SLD } \\
\hline & & & $\begin{array}{c}\text { X-rays } \\
\left(\times 10^{10} \mathrm{~cm}^{-2}\right)\end{array}$ & $\begin{array}{l}\text { Neutrons } \\
\left(\times 10^{10} \mathrm{~cm}^{-2}\right)\end{array}$ \\
\hline Quartz & $\mathrm{SiO}_{2}$ & 2.65 & 22.5 & 4.2 \\
\hline Albite & $\mathrm{NaAlSi}_{3} \mathrm{O}_{8}$ & 2.62 & 22.1 & 4.0 \\
\hline Muscovite & $\mathrm{KAl}_{2}\left(\mathrm{AlSi}_{3} \mathrm{O}_{10}\right)(\mathrm{OH})_{2}$ & 2.90 & 24.5 & 3.9 \\
\hline Illite & $\mathrm{K}(\mathrm{Al}, \mathrm{Fe}, \mathrm{Mg})_{2}(\mathrm{Si}, \mathrm{Al})_{4} \mathrm{O}_{10}(\mathrm{OH})_{2}$ & 2.75 & 23.1 & 3.7 \\
\hline Calcite & $\mathrm{CaCO}_{3}$ & 2.71 & 23.0 & 4.6 \\
\hline Dolomite & $\mathrm{CaMg}\left(\mathrm{CO}_{3}\right)_{2}$ & 2.87 & 24.3 & 5.4 \\
\hline Apatite & $\mathrm{Ca}_{5}\left(\mathrm{PO}_{4}\right)_{3}(\mathrm{OH}, \mathrm{F}, \mathrm{Cl})$ & 3.19 & 26.9 & 4.1 \\
\hline Pyrite & $\mathrm{FeS}_{2}$ & 4.93 & 40.5 & 3.7 \\
\hline
\end{tabular}

357 For neutrons, minerals SLD are close to each other $\left(\sim 4.10^{10} \mathrm{~cm}^{-2}\right)$ which allows to consider 358 minerals as a homogeneous phase. The corresponding mean value is easily assessed using Equation 8 359 with volume fraction of each mineral determined by XRD. For X-rays, most of the minerals have a 360 SLD value close to $24.10^{10} \mathrm{~cm}^{-2}$, except pyrite. Thus, X-ray perceives the minerals as two distinct 361 phases since differences in SLD give rise to a contrast.

\section{Kerogen:}

363 Kerogen in analogous materials such as coal, ${ }^{7}$ is described as a homogeneous phase where its SLD 364 is similar whatever the macerals type.

365 Since our sample selection was designed to obtain a continuous sequence of increasing maturity, it is 366 mandatory to consider the effect of maturity on kerogen SLD. A recent study on kerogen in source 367 rocks, ${ }^{71}$ show that neutron kerogen SLD vary from $1.10^{10} \mathrm{~cm}^{-2}$ for immature kerogen up to $4.10^{10} \mathrm{~cm}^{-2}$ 368 for the overmature one. Elemental compositions and densities of gas shale from various maturities and 
369 after acid attack, given by Thomas and coworkers (2014), ${ }^{71}$ were used here to assess neutron and X370 ray SLD as well as mass densities of kerogens. Thus, we assumed that all the Fe content in attack acid 371 residues is only due to pyrite $\mathrm{FeS}_{2}$. The pyrite contribution, including the sulfur one, has been 372 subtracted to obtain elemental composition and densities of model kerogens containing $\mathrm{C}, \mathrm{H}, \mathrm{O}$ and $\mathrm{N}$ 373 atoms. X-ray and neutron SLD were assessed using Equation 7. Results are plotted on Figure 8 as a 374 function of kerogen densities. Indeed, kerogen density vary in the same way as vitrinite reflectance 375 and could be used as a maturity index.

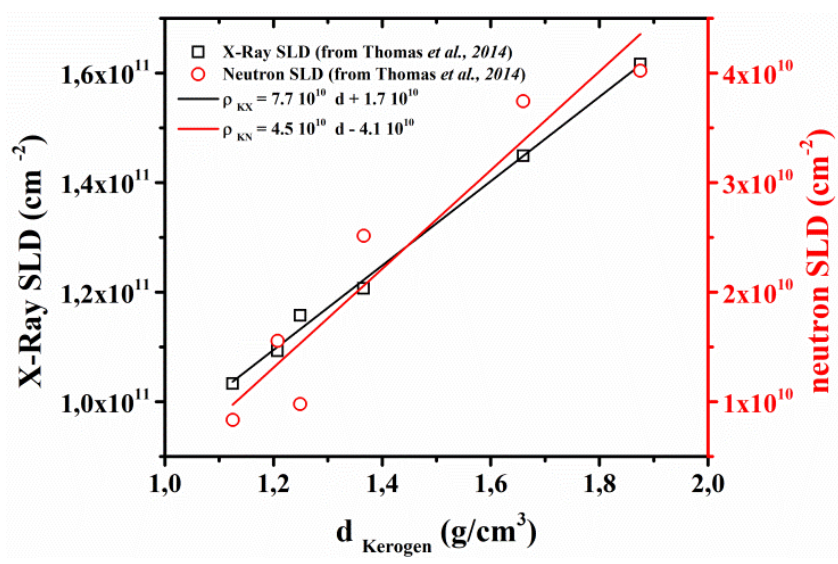

376 Figure 8. X-ray and neutron kerogen SLD as a function of kerogen densities based on data from

377 Thomas et al., 2014. ${ }^{71}$ X-ray linear regression (black curve) and neutron linear regression (red curve) for kerogen SLD estimations.

379 Linear regressions were performed on kerogen X-ray and neutron SLD. From these linear 380 regressions, $\rho_{K N}$ and $\rho_{K X}$ can be expressed as :

$$
\rho_{K N}=4 \cdot 5 \cdot 10^{10} \cdot d-4 \cdot 1 \cdot 10^{10}
$$

382 and

$$
\boldsymbol{\rho}_{K X}=7 \cdot 7 \cdot 10^{10} \cdot d+1 \cdot 7 \cdot 10^{10}
$$

383 with $\rho$ in $\mathrm{cm}^{-2}$ and $d$ in $\mathrm{g} / \mathrm{cm}^{3}$. 


\section{Pore space :}

386 For this study, four model fluids are considered : air, methane in gaseous form, toluene and pentane.

387 SLD values are listed in Table 4 below.

Table 4. Model Fluids SLD calculated from equation 7.

\begin{tabular}{ccc}
\hline Model fluids & $\begin{array}{c}\text { Neutrons SLD } \\
\left(\times 10^{10} \mathrm{~cm}^{-2}\right)\end{array}$ & $\begin{array}{c}\text { X-Ray SLD } \\
\left(\times 10^{10} \mathrm{~cm}^{-2}\right)\end{array}$ \\
\hline Toluene & 0.9 & 8.0 \\
\hline Pentane & -0.6 & 6.2 \\
\hline Methane $_{(\mathrm{g})}$ & 0.0 & 0.0 \\
\hline Air & 0.0 & 0.0 \\
\hline
\end{tabular}

Pores can be fulfilled by gaseous species and/or by condensed hydrocarbons. If the pore space is 390 fulfilled by a gas, its SLD for both X-ray and neutron is close to 0 . If condensed fluids are in the pore 391 space, it is then assumed that neutron SLD is almost null as condensed fluids have a SLD value 392 ranging from $1.10^{10} \mathrm{~cm}^{-2}$, for aromatic fluids, to $-0.510^{10} \mathrm{~cm}^{-2}$ for aliphatic fluids. For X-ray, pore 393 space SLD will be close to $8.10^{10} \mathrm{~cm}^{-2}$ for aromatics fluids and around $6.10^{10} \mathrm{~cm}^{-2}$ for aliphatic fluids.

From these different SLD values, it appears that since neutron overmature kerogen and 396 minerals SLD values are close, neutron scattering acquired on overmature gas shales could be 397 interpreted in the frame of a two-phases system. As shown in Figure 8, for immature and mature 398 kerogen, SLD values are much lower than the SLD of the mineral phase. Consequently, the two-phase 399 system, which is classically used to described source rock scattering data, is less relevant than a three400 phases one. Concerning the nature of pore content, it is clear that neutron cannot distinguish gas from 401 hydrocarbons whereas X-ray can. For X-ray SLD values, four phases have different SLD : pyrite, 
others minerals, kerogen and pore space. From XRD measurements, pyrite content is low, less than 2.5

403 vol \%, in the studied source rocks. Moreover, FESEM observations reveals that a large part of pyrite is

404 present as grains with sizes higher than $1 \mu \mathrm{m}$. These grains will contribute to X-ray scattering in a $Q$

405 range that is not probed by our instrument. Firstly, pyrite is therefore neglected and its contribution

406 will be discussed after data modeling. Hence, for both types of radiation, at least three SLD values has

407 to be considered rather than a two-phase approximation.

408

409 3.1.2. Scattering intensity. As shown in FESEM observations, samples are described as a four 410 phases system : pyrite, other minerals, kerogen and pores. Even if pyrite is discarded, we will 411 distinguish for scattering four phases, namely minerals, kerogen, pores included in kerogen and pores 412 in minerals. For that purpose, source rocks system can be defined as follows:

$$
\sum_{i=1}^{4} H_{i}(\vec{r})=H_{M}(\vec{r})+H_{K}(\vec{r})+H_{P}(\vec{r})+H_{P^{\prime}}(\vec{r})=1
$$

414 Where $H_{M}(\vec{r}), H_{K}(\vec{r}), H_{P}(\vec{r})$ and $H_{P \prime}(\vec{r})$ are respectively, the characteristic functions of the 415 minerals, the kerogen, the pores contained in the kerogen and the pores in minerals. From previous 416 equation, the amplitude $A(Q)$ of neutrons or X-ray can be written as :

$$
A(Q)=\int_{V}\left[\sum_{i=1}^{4} \rho_{i} H_{i}(\vec{r})\right] e^{-i q r}
$$

418 Since $\sum_{i=1}^{4} H_{i}(\vec{r})=1$ and fluctuations of SLD occur, an arbitrary SLD reference can be chosen to 419 determine $\rho_{i} H_{i}(\vec{r})$ in regard to the phase of interest, the kerogen, as :

$$
\sum_{i=1}^{4} \rho_{i} H_{i}(\vec{r})=\left(\rho_{M}-\rho_{K}\right) H_{M}(\vec{r})+\left(\rho_{P}-\rho_{K}\right) H_{P}(\vec{r})+\left(\rho_{P \prime}-\rho_{K}\right) H_{P \prime}(\vec{r})+\rho_{K}
$$


$421 A(Q)$ can be rewritten according to the phase of interest through the Fourier transform. We note that

422 the Fourier transform of $\rho_{K}$ is a dirac centered at $Q=0$ and do not appear in the amplitude expression:

$$
A(Q)=\left(\rho_{M}-\rho_{K}\right) \widetilde{H_{M}}(R)+\left(\rho_{P}-\rho_{K}\right) \widetilde{H_{P}}(R)+\left(\rho_{P \prime}-\rho_{K}\right) \widetilde{H_{P}}(R)
$$

424 From $A(Q)$, the scattering intensity is expressed according to $I(Q)=A(Q) A(Q) *{ }^{* 4}$ The crossed 425 terms are considered negligible owing to FESEM observations revealing no correlation between the 426 kerogen and the pores contained in the mineral matrix. Arthur and Cole (2014) have shown by a 427 FESEM/FIBSEM dual beam analysis that the mesopores are mainly contained in the organic matter. In 428 addition, Bazilevskaya and coworkers (2015) demonstrated that about $50 \%$ of the porosity cannot be 429 observed by direct space analysis and may be contained in the organic matter or the interlayer of 430 clayey minerals. Thus, the scattering intensity is expressed as :

$431 \quad \boldsymbol{I}(\boldsymbol{Q})=\left(\boldsymbol{\rho}_{\boldsymbol{M}}-\boldsymbol{\rho}_{\boldsymbol{K}}\right)^{2} \widetilde{\boldsymbol{H}_{\boldsymbol{M}}}(\boldsymbol{Q}) \widetilde{\boldsymbol{H}_{M}}(\boldsymbol{Q})+\left(\boldsymbol{\rho}_{\boldsymbol{P}^{\prime}}-\boldsymbol{\rho}_{\boldsymbol{K}}\right)^{2} \widetilde{\boldsymbol{H}_{\boldsymbol{P}^{\prime}}}(\boldsymbol{Q}) \widetilde{\boldsymbol{H}}_{\boldsymbol{P}^{\prime}}^{*}(\boldsymbol{Q})+\left(\boldsymbol{\rho}_{\boldsymbol{p}}-\boldsymbol{\rho}_{\boldsymbol{K}}\right)^{2} \widetilde{\boldsymbol{H}_{\boldsymbol{P}}}(\boldsymbol{Q}) \widetilde{\boldsymbol{H}}_{\boldsymbol{P}}^{*}(\boldsymbol{Q})$ 432

434 At this point, the scattering intensity as illustrated in Figure 6 can be described as the sum of three 435 contributions depending on a four phase system which are defined using three terms of contrast.

436 The first contribution is related to the contrast between mineral and kerogen phases. Based on 437 FESEM observations, kerogen is in the form of micrometric to nanometric domains and its volume 438 fraction, related to the TOC content, is few percent. A strong scattering intensity at small $Q$ values is 439 then expected for this contribution. Indeed, at low $Q$ values, the curve trend appears to be a power law 440 which can be expressed as $A \cdot Q^{-\alpha}$, with $\alpha$ close to $3, A$ being a prefactor explicited later. In source and 441 sedimentary rocks studies, the $\alpha$ exponent is sometimes related to a surface fractal dimension $D s$ by $442 \alpha=6-D s$ where Ds is restricted to $2<D s \leq 3 .^{75-77}$ Schmidt $(1982),{ }^{78}$ shows that the $\alpha$ exponent 
443 could be also related to power law size distribution $f(R) \sim R^{-(l-D s)}$. Whatever the physical meaning of 444 power law intensity dependence, we will consider $\alpha$ as a fitting parameter and concentrate on the 445 prefactor $A$ that could be expressed as the product of squared contrast factor $\left(\rho_{M}-\rho_{K}\right)^{2}$ by a factor $a$ 446 related to the structural arrangement of kerogen in the mineral matrix. Hence, the first term of $447 \quad$ Equation 15 would be $a\left(\rho_{M}-\rho_{K}\right)^{2} Q^{-\alpha}$

448 The second contribution, as highlighted by the FESEM characterizations, is related to pores in 449 mineral phases, which are mainly macropores diluted within the mineral matrix. The mineral/pores 450 interface seems to be smooth and their sizes vary from macrofractures to macropores. Consequently, 451 their contribution likely follows a Porod behavior $\left(I(Q) \sim Q^{-4}\right)$ which starts at lower $Q$ values and 452 strongly decreases toward higher $Q$ values. At least, this means that this contribution to $I(Q)$ is 453 negligible in the high $Q$ domain probed.

454 The last contribution is related to the distribution of micropores in the kerogen matrix. As pores 455 shape and size couldn't be well defined, owing to limitations (resolution and/or statistical 456 representativeness), by direct space analysis such as FESEM or transmission electron microscopy, it is 457 assumed that pores have a variety of shape and size as source rocks are natural materials. Both 458 assumptions lead to a smoothing of the scattering curve compared to unique size and shape pores and 459 make difficult to deconvolute both effects. In this study, we fixed the shape of the considered objects 460 as spherical for sake of simplicity and assumed that size are distributed. This assumption preserve the 461 physical meaning of the average size of the pores and it associated volume fraction. In source rocks 462 the pore size distribution is often considered as peaked like in gas adsorption/desorption ${ }^{17,27,28,41}$ or $463 \mathrm{NMR}^{34,46}$ analysis. The $\widetilde{H_{P}}(Q) \widetilde{H}_{P}^{*}(Q)$ term is expressed as $n \int_{R_{\min }}^{R_{\max }} f_{P}(R) V_{P}^{2}(R) P(Q, R) d R \quad$ - a diluted 464 dispersion of pores - where $n$ is the number density of pores, $V_{p}(R)$ stand for the volume of pore of size 
$R, P(Q, R)$ is the form factor of the pores $(P(0, R)=1)$ chosen here as spherical, and $f_{P}(R)$ the

466 normalized number size distribution function chosen here for convenience as log normal :

$$
f_{P}(R)=\frac{1}{\sigma \sqrt{2 \pi}} \exp \left(-\frac{\ln (R / \mu)^{2}}{2 \sigma^{2}}\right)
$$

468 Where $\mu$ the mean value of sphere radius and $\sigma$ the size polydispersity.

469 Accordingly, for the scattering vector range measured in this study, a three-phase system with two 470 main contributions, is defined and expressed, for $\mathrm{X}$-rays $(\mathrm{X})$ and neutrons $(\mathrm{N})$ as :

$$
I(Q)_{X, N}=a\left(\rho_{M}-\rho_{K}\right)_{X, N}^{2} Q^{-\alpha}+n\left(\rho_{P}-\rho_{K}\right)_{X, N}^{2} \int_{R_{\min }}^{R_{\max }} f_{P}(R) V_{P}^{2}(R) P(Q, R) d R
$$

472 In this equation, parameters giving a direct influence on the intensity $Q$ dependence, namely $\alpha, \sigma$ 473 and $\mu$, should be retrieved separately by fitting procedures. They provides details on each contribution 474 prevailing in different $Q$ domains. By contrast, only global prefactors $A=a\left(\rho_{M}-\rho_{K}\right)^{2}$ and $N=$ $475 n\left(\rho_{P}-\rho_{K}\right)^{2}$ that adjust the amplitude of each $Q$ dependence, will be extracted from the modeling.

\subsection{Anisotropy}

478 First, we consider the $I(Q)$ behavior for the two azimuthal sectors $\varphi_{1}$ and $\varphi_{2}$ according to Figure 479 7(a). Both scattering techniques results are illustrated in Figure 9 for SANS and in Figure 10 for 480 SAXS/WAXS. It is noted that the MT-1 sample gives isotropic 2D pattern. As detailed in the 481 literature, scattering data on source rocks follow at small $Q$ values an algebraic trend assimilated to 482 A. $Q^{-\alpha .8,20-23,27,35,71,79,80}$ In both techniques, the $\alpha$ parameter, reported in Table 6 , have similar values 483 close to 3 and the intensity ratio between $\varphi_{1}$ and $\varphi_{2}$ remains constant until a breakdown around $0.03 \AA^{-}$ 
$484{ }^{1}$ in SANS and $0.1 \AA^{-1}$ in SAXS/WAXS. For larger $Q$ values the scattering intensity is quite similar 485 whatever the azimuthal sector. This behavior is ascribed to :

486 - anisotropic scattering at small $Q$ values likely due to preferential orientation of low 487 dimensionality particles such as clays and micas.

$488 \quad-\quad$ isotropic scattering at large $Q$ values reminiscent of spherical nanopores located in the kerogen

489 A further confirmation of this attribution is shown in supplementary information where the high $Q$ 490 intensity signal is ranked as the one of TOC content.
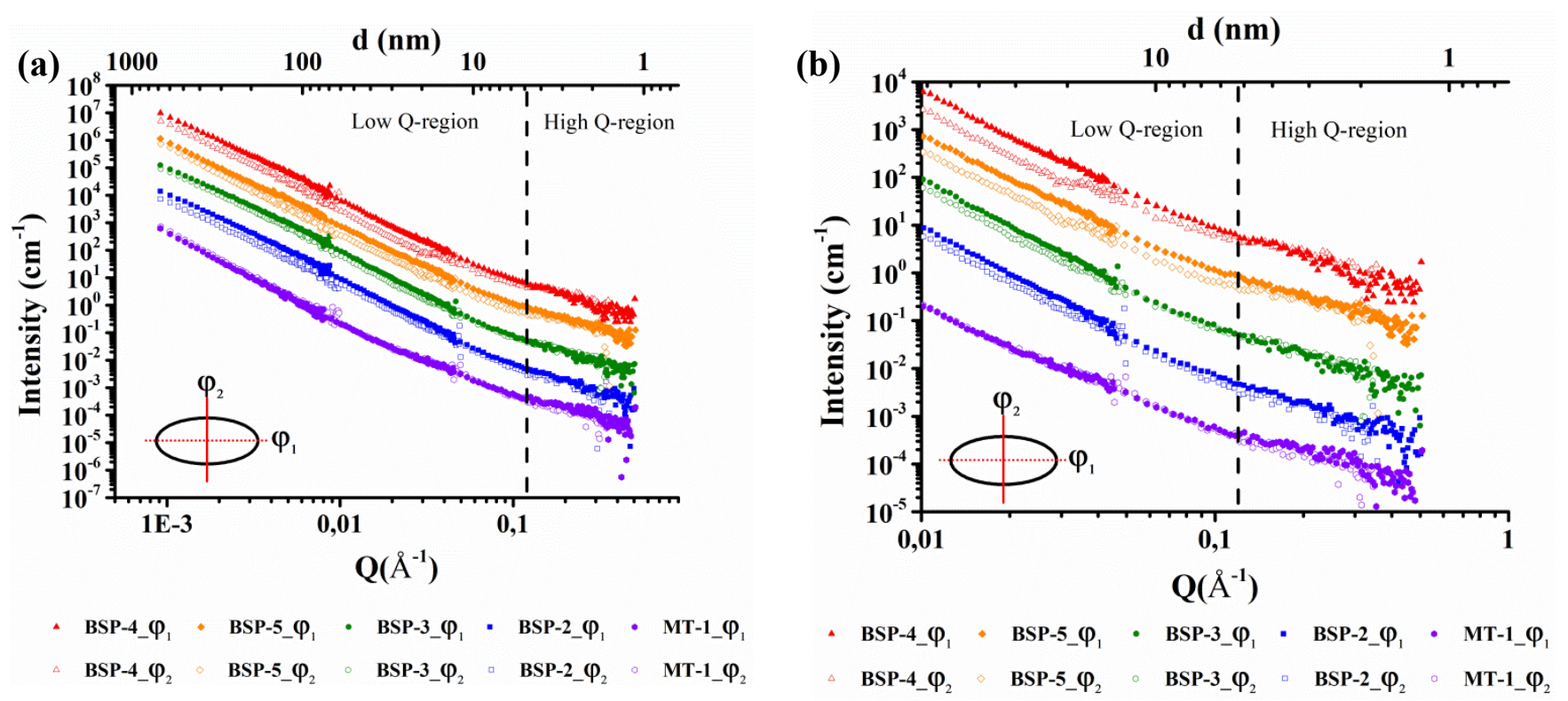

$491 \quad$ Figure 9. (a) Samples SANS profiles according to the azimuthal area of interest. Full dots represent

492 data obtained for $\varphi_{1}=0^{\circ}$ and empty dots are data coming from $\varphi_{2}=90^{\circ}$. (b) Zoom on SANS profiles

493 to match the Q-range of SAXS/WAXS data. In both graphs, SANS profiles of MT-1, BSP-2, BSP-5 and 494 BSP-4 are scaled vertically according to the scale factors 0.01, 0.1, 10 and 100, respectively. 


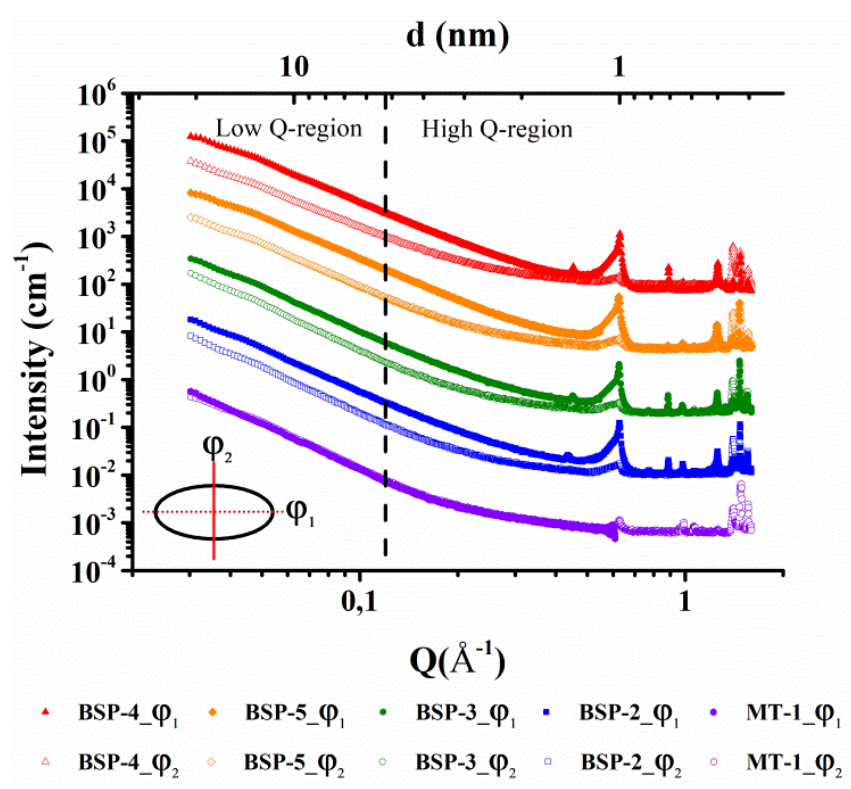

Figure 10. (a) Samples SAXS/WAXS profiles according to the azimuthal area of interest. Full dots represent data obtained for $\varphi_{1}=0^{\circ}$ and empty dots are data coming from $\varphi_{2}=90^{\circ}$. SAXS $/$ WAXS

497 profiles of $M T-1, B S P-2, B S P-5$ and BSP-4 are scaled vertically according to the scale factors 0.003, 0.05, 15 and 300, respectively.

499 Secondly, we consider the $I(\varphi)$ behavior in the two $Q$ ranges $S 1$ and $S 2$ according to Figure $7(b)$. 500 Samples data (dots) and fitting curves (lines) to the Maier-Saupe function (Equation 1) are illustrated 501 in Figure 11(a) for low $Q$-region and Figure 11(b) for high $Q$ values. At first sight, from MT-1 to 502 BSP-4 samples an increasing intensity and sharpness of the distribution along the azimuthal angle is 503 observed in both regions. Three groups are distinguished, the MT-1 isotropic sample with a flat 504 intensity, the BSP-2/BSP-3 group exhibiting a broad distribution and the BSP-4/BSP-5 which have the 505 highest and sharper distribution. In the Figure 11(b), as the BSP-5 sample does not possess chlorite in 506 SAXS profile, its intensity along the azimuthal angle is smaller than for BSP-4. 

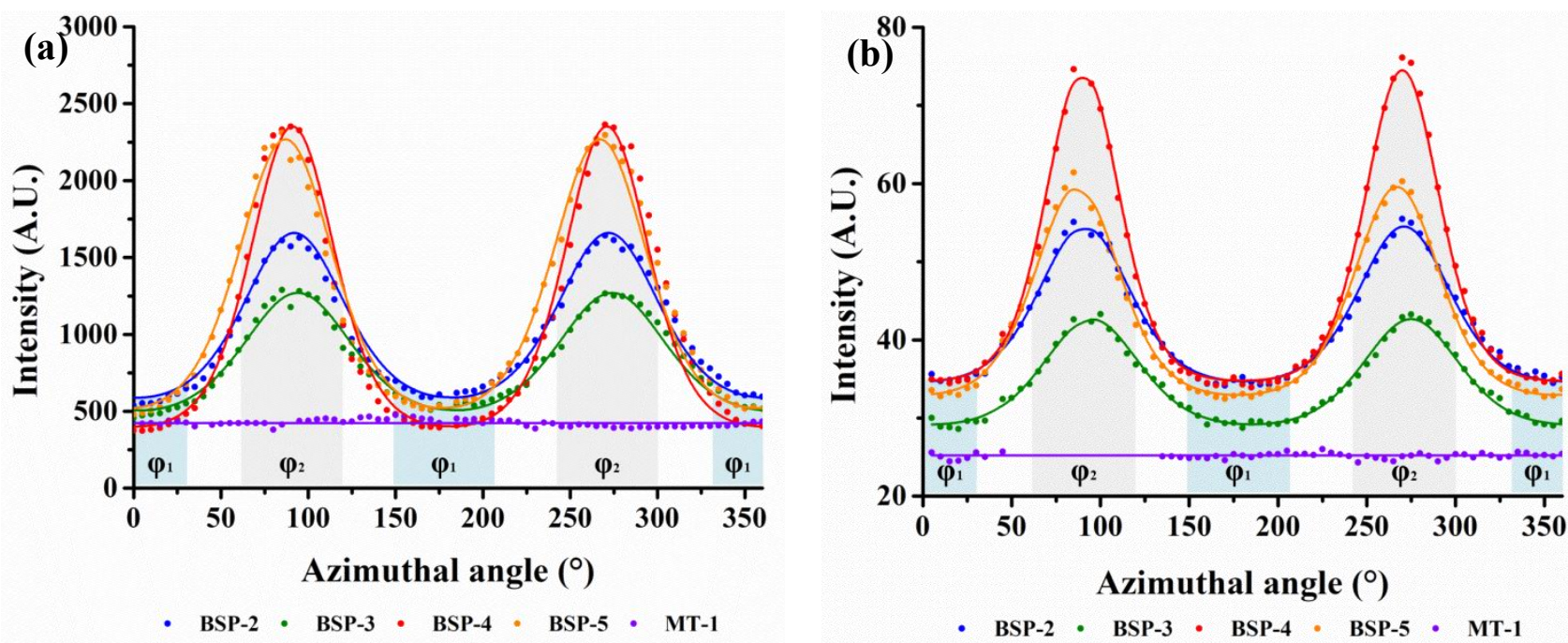

Figure 11. SAXS azimuthal integration profiles of BSP and MT samples within (a) low Q-region

$\left(Q=5.10^{-2}\right.$ to $\left.0.2 A^{-1}\right)$ and $(b)$ high $Q$-region $\left(Q=0.34\right.$ to $\left.0.5 A^{-1}\right)$. Integrated azimuthal angle regions

from profiles decomposition are illustrated by the light blue and light grey areas respectively for $\varphi_{1}$ and for $\varphi_{2}$.

As shown in Table 5, it is possible from these data, to apply the Maier-Saupe fitting function to extract $A, B, m$ and $\psi$ parameters and then to calculate the order parameter $S$. Values of $\psi$ are close to

$51390^{\circ}$ suggesting that anisotropic particles align preferentially with their long axis parallel to the bedding 514 plane. Order parameters for BSP samples at low $Q$ values are ranking from 0.13 and 0.14 , for BSP-3 515 and BSP-2, up to 0.21 and 0.26 , for BSP-5 and BSP-4. Whereas, in the high $Q$-region, this parameter 516 is quite low, barely reaching 0.09 at its maximum for BSP-4. BSP-2 and BSP-3 exhibit the lowest 517 values with $\mathrm{S}=0.06$. Then, BSP-5 have an order parameter of 0.08 . This seems to indicate that this 518 part of the signal is less anisotropic and is dominated by an isotropic pattern. For MT-1, as its 2D 519 scattering pattern is isotropic, $S$ parameters for both $Q$ regions is equal to 0. 


\begin{tabular}{cccccc|ccccc}
\hline Reference & \multicolumn{6}{c|}{ Low Q region : $\mathbf{5 . 1 0 ^ { - 2 }}$ to 0.2 $\AA^{-1}$} & \multicolumn{5}{c}{ High Q region : 0.34 to 0.5 $\AA^{-1}$} \\
& $\mathrm{~A}$ & $\mathrm{~B}$ & $\mathrm{~m}$ & $\psi$ & $\mathrm{S}$ & $\mathrm{A}$ & $\mathrm{B}$ & $\mathrm{m}$ & $\psi$ & $\mathrm{S}$ \\
\hline BSP-2 & 418.6 & 168.8 & 2.0 & 92 & 0.14 & 28.6 & 4.4 & 1.8 & 91 & 0.06 \\
\hline BSP-3 & 324.8 & 181.1 & 1.6 & 94 & 0.13 & 22.6 & 5.6 & 1.4 & 95 & 0.06 \\
\hline BSP-4 & 304.1 & 96.6 & 3.1 & 91 & 0.26 & 32.3 & 1.1 & 3.6 & 90 & 0.09 \\
\hline BSP-5 & 342.1 & 177.1 & 2.4 & 87 & 0.21 & 28.9 & 2.5 & 2.5 & 87 & 0.08 \\
\hline MT-1 & 423.4 & 0.0 & 0.0 & 0.0 & 0.0 & 24.7 & 0.0 & 0.0 & 0 & 0.0 \\
\hline
\end{tabular}

523

The separation of the global signal into an anisotropic and an isotropic contribution allows to specify a more accurate expression for $Q$ dependence of intensity :

$$
I(Q)_{X, N}=a(\varphi)\left(\rho_{M}-\rho_{K}\right)_{X, N}^{2} Q^{-\alpha}+n\left(\rho_{P}-\rho_{K}\right)_{X, N}^{2} \int_{R_{\min }}^{R_{\max }} f_{P}(R) V_{P}^{2}(R) P(Q, R) d R
$$

$$
\text { where the prefactor } a \text { has been substituted by } a(\varphi) \text {. }
$$

\subsection{Multiscale structure.}

We took advantage of anisotropic scattering to consider, in the fitting procedure based on equation 19 , the data acquired in azimuthal sector $\varphi_{2}$. Indeed, for this sector, the scattering intensity from the first term of equation 19 is minimized and allows to better evaluate the second term contribution that remain moderate. This strategy could be optimized by considering a much smaller angular sector $\Delta \varphi_{2}$ but it would require much larger acquisition time. Hence, SANS and SAXS/WAXS " $\varphi_{2}$ " data related to the five source rocks were fitted to equation 19 by using SASFit software. ${ }^{81}$ Results represented in Figure 12(a) for SANS data and in Figure 12(b) for SAXS/WAXS measurements shows a good 
agreement between model and data for the both radiation on the whole $Q$ range. Geometrical

539 parameters $(\alpha, \mu$ and $\sigma)$, reported in Table 6, are first assessed by fitting SANS data as the Q

540 dependence of these latter are more pronounced than for SAXS data. Then, modelling was performed

541 based on a simultaneous scattering fit of SAXS/SANS data to obtain the pre-factors $a\left(\rho_{M}-\rho_{K}\right)^{2}$ and

$542 n\left(\rho_{P}-\rho_{K}\right)^{2}$, containing the SLD of each phase and depending on the type of radiation.

543 Results obtained for geometrical parameters indicate that both SANS and SAXS/WAXS scattering

544 intensity can be described as the sum of two types of contributions using the same parameters giving

545 the $Q$ dependence, namely $\alpha, \mu$ and $\sigma$. These results also validate the SANS incoherent scattering

546 background subtraction based on mean value measured at high Q values .

547 The $\alpha$ parameters, that are close to each other $(3.1-3.25)$ for BSP samples and slightly higher (3.4)

548 for MT1, are in the range of reported values. ${ }^{8,10,14,20,23,27,28,35,39,79}$ The widths $\sigma$ of nanopore size

549 distributions are quite narrow, always close to 0.2 and the fitted parameters given here are obtained

550 with values of $\sigma$ set to 0.2 for a better visibility. The mean radius of nanopores is close to $0.5 \mathrm{~nm}$, a

551 value commonly found for this type of material. ${ }^{20,79}$ For the overmature sample, the curves at high $Q$

552 values show clearly two separate bumps assigned here to two pore size distributions. The first one has

553 a mean radius of $0.5 \mathrm{~nm}$ in the same range as the mature samples and the second one has much higher

554 values close to $3.5 \mathrm{~nm}$. In addition, it appears that SAXS techniques can also provide information on

555 porous media in the kerogen phase as both SANS and SAXS/WAXS profiles are in good agreement

556 using pore size define from SANS modeling. From fitting data, BSP samples are described as source

557 rocks with pore radii varying from 0.5 , for BSP-3, BSP-4 and BSP-5, up to $0.7 \mathrm{~nm}$, for BSP-5. MT-1

558 sample displays two pore radii $0.5 \mathrm{~nm}$ and $3.5 \mathrm{~nm}$. In addition, fit sensitivity on the pore size radius

559 was tested as shown in supplementary information. It shows that radii nanopore measurements are

560 sensitive within $\sim 1-2$ Å range. 


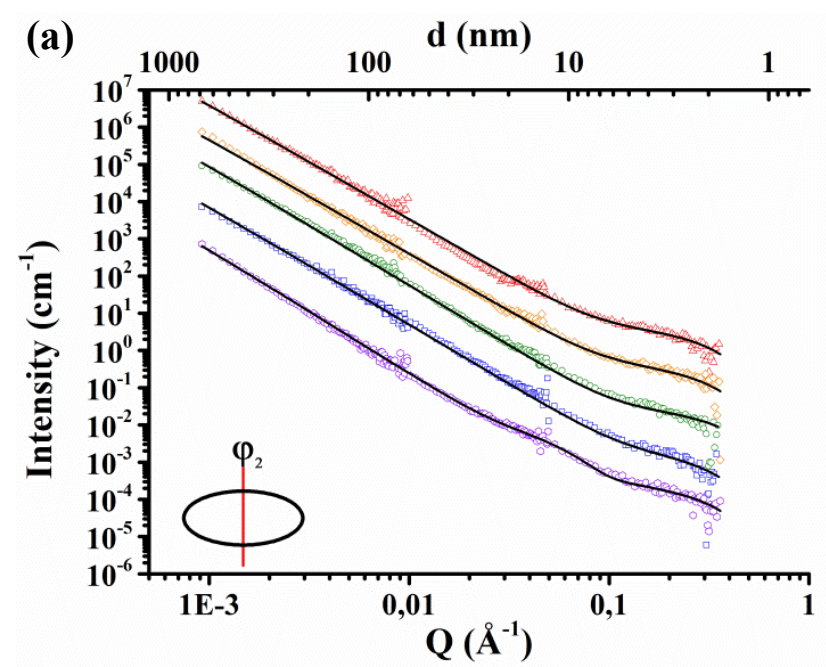

BSP-4_ $\varphi_{2} \circ$ BSP-5_ $\varphi_{2} \circ$ BSP-3_- $\varphi_{2}$ 口 BSP-2_ $\varphi_{2} \circ$ MT-1_ $\varphi_{2}$

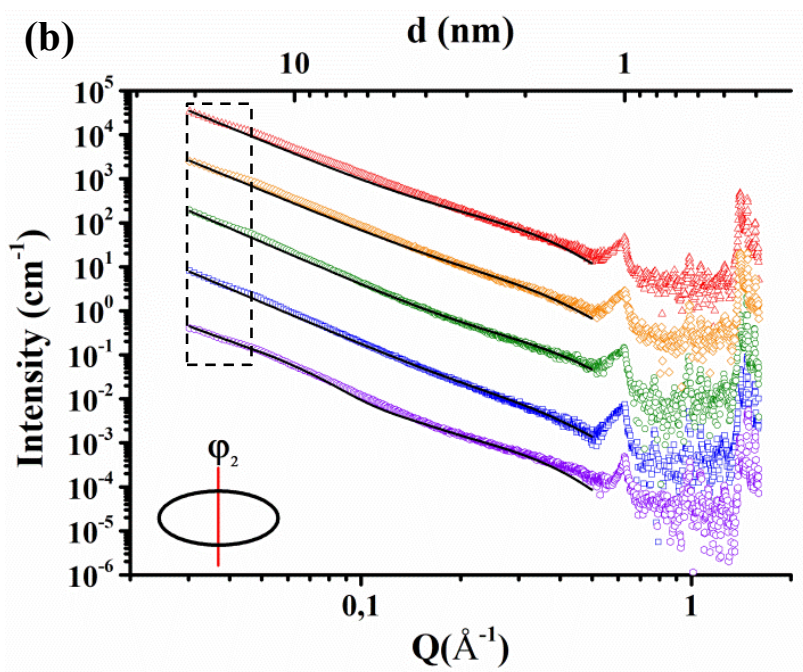

BSP-4_ $\varphi_{2} \circ$ BSP-5_ $\varphi_{2} \circ$ BSP-3_ $\varphi_{2} \circ$ BSP-2_ $\varphi_{2} \circ$ MT-1_ $\varphi_{2}$

$561 \quad$ Figure 12. (a) Samples SANS and fit profiles coming from data integrated along the azimuthal angle

$562 \varphi_{2}=90^{\circ}$. SANS profiles of MT-1, BSP-2, BSP-5 and BSP-4 are scaled vertically according to the scale

563 factors 0.01, 0.1, 10 and 100, respectively. (b) Samples SAXS/WAXS and fit profiles from data

564 acquired along the azimuthal angle $\varphi_{2}=90^{\circ} . S A X S / W A X S$ profiles of $M T-1, B S P-2, B S P-5$ and $B S P-4$

565 are scaled vertically according to the scale factors 0.003, 0.05, 15 and 300, respectively. In both

566 graphs, solid lines represent the sum of $f(R)$ and $f_{P}(R)$ contributions determined with SASfit software.

Table 6. Fitting parameters of SANS and SAXS data obtained for the a parameter and the term of

569 contrast $A=a(\varphi)\left(\rho_{M}-\rho_{K}\right)_{N}^{2}$ related to the A. $Q^{-\alpha}$ contribution and also the radius $(\mu)$ and the term of contrast $n\left(\rho_{P}-\rho_{K}\right)_{N}^{2}$ related to the log normal contribution.

\begin{tabular}{ccc|cc|cc}
\hline \multirow{2}{*}{ Reference } & $\alpha$ & mu & \multicolumn{2}{|c|}{ Neutrons } & \multicolumn{2}{c}{ X-rays } \\
& & $(\mathrm{nm})$ & $\boldsymbol{a}(\boldsymbol{\varphi})\left(\boldsymbol{\rho}_{M}-\boldsymbol{\rho}_{K}\right)_{N}^{2}$ & $\boldsymbol{n}\left(\boldsymbol{\rho}_{P}-\boldsymbol{\rho}_{K}\right)_{N}^{2}$ & $\boldsymbol{a}(\boldsymbol{\varphi})\left(\boldsymbol{\rho}_{M}-\boldsymbol{\rho}_{K}\right)_{N}^{2}$ & $\boldsymbol{n}\left(\boldsymbol{\rho}_{P}-\boldsymbol{\rho}_{K}\right)_{N}^{2}$ \\
\hline BSP-2 & 3.20 & 0.7 & 4.4 & 0.6 & 4.9 & 0.6 \\
\hline BSP-3 & 3.25 & 0.5 & 3.4 & 4.4 & 4.4 & 3.5 \\
\hline BSP-4 & 3.10 & 0.5 & 6.4 & 3.6 & 7.2 & 5.6 \\
\hline BSP-5 & 3.10 & 0.5 & 7.6 & 6.3 & 11.0 & 5.2 \\
\hline
\end{tabular}




\begin{tabular}{|c|c|c|c|c|c|c|}
\hline MT-1 & 3.40 & 0.5 & 0.4 & 4.0 & 1.2 & 6.2 \\
\hline & & 3.5 & & 9.0 & & 2.9 \\
\hline
\end{tabular}

572 Regarding the prefactors, we first consider their ratios $R_{A}$ and $R_{N}$ since they depend only on squared 573 contrast terms.

574

575

576

and

$$
\begin{aligned}
\sqrt{\boldsymbol{R}_{A}} & =\frac{\left(\rho_{M N}-\rho_{K N}\right)_{N}}{\left(\rho_{M X}-\rho_{K X}\right)_{X}} \\
\boldsymbol{R}_{N} & =\frac{N_{N}}{N_{X}}=\frac{n\left(\rho_{P N}-\rho_{K N}\right)_{N}^{2}}{n\left(\rho_{P X}-\rho_{K X}\right)_{X}^{2}}
\end{aligned}
$$

$$
R_{A}=\frac{A_{\varphi, N}}{A_{\varphi, X}}=\frac{a\left(\varphi_{2}\right)\left(\rho_{M N}-\rho_{K N}\right)_{N}^{2}}{a\left(\varphi_{2}\right)\left(\rho_{M X}-\rho_{K X}\right)_{X}^{2}}
$$

The equation $20 \mathrm{~b}$, together with the equations 9 and 10 relating the neutron and X-ray kerogen SLD to the kerogen density $d$, form a system of three equations with three unknown $\left(\rho_{K N}, \rho_{K X}\right.$ and $\left.d\right)$ that could be easily solved. The extracted parameters are reported on Table 7 for samples of various maturity. It appears that the extracted densities are quite similar - about $1.65 \mathrm{~g} / \mathrm{cm}^{3}$ - for the BSP samples and markedly different $-1.74 \mathrm{~g} / \mathrm{cm}^{3}-$ for the MT1. It points out that BSP samples are mature and MT1 overmature source rock as expected from Rock-Eval pyrolysis measurements (section 2.3.). Regarding the neutron SLD, the one of overmature source rock $-3.7 .10^{10} \mathrm{~cm}^{-2}-$ is quite similar to the one of mineral, suggesting that the scattering data could have been interpreted in the frame of a twophase system. Conversely, the neutron SLD differences between minerals and kerogen for the mature source rocks are noticeable $\left(0.5-0.7 .10^{10} \mathrm{~cm}^{-2}\right)$, justifying the three phases approximation developed here. Regarding X-ray, the large differences between minerals and kerogen SLD show clearly that the 590 three-phase approximation is mandatory to interpret properly SAXS measurements. 
Table 7. Values for $\rho_{M N}$ and $\rho_{M X}$ are calculated from equation 7. Kerogen densities, $\rho_{K N}, \rho_{K X}$ and

\begin{tabular}{|c|c|c|c|c|c|c|c|c|c|}
\hline \multirow{2}{*}{ Sample } & mu & $\mathbf{n}$ & $\begin{array}{l}\text { Volume } \\
\text { fraction }\end{array}$ & $\begin{array}{l}\text { Kerogen } \\
\text { density } d\end{array}$ & $\rho_{M N}$ & $\rho_{M X}$ & $\rho_{K N}$ & $\rho_{K X}$ & $\rho_{P X}$ \\
\hline & $(\mathrm{nm})$ & $\left(\mathrm{x} 10^{19} \mathrm{~cm}^{-3}\right)$ & $\left(\mathrm{x} 10^{-2}\right)$ & $\left(\mathrm{g} / \mathrm{cm}^{3}\right)$ & $\left(\mathrm{x} 10^{10} \mathrm{~cm}^{-2}\right)$ & $\left(\mathrm{x} 10^{10} \mathrm{~cm}^{-2}\right)$ & $\left(\mathrm{x} 10^{10} \mathrm{~cm}^{-2}\right)$ & $\left(x 10^{10} \mathrm{~cm}^{-2}\right)$ & $\left(\mathrm{x} 10^{10} \mathrm{~cm}^{-2}\right)$ \\
\hline BSP-2 & 0.7 & 0,5 & 1.0 & 1.66 & 4.0 & 21.3 & 3.4 & 14.5 & 4.3 \\
\hline BSP-3 & 0.5 & 4.7 & 3.0 & 1.67 & 4.0 & 21.3 & 3.4 & 14.6 & 5.1 \\
\hline BSP-4 & 0.5 & 6.0 & 3.8 & 1.59 & 3.7 & 20.3 & 3.0 & 14.0 & 4.4 \\
\hline BSP-5 & 0.5 & 5.7 & 3.6 & 1.65 & 3.8 & 20.2 & 3.3 & 14.4 & 4.9 \\
\hline MT-1 & 0.5 & 2.6 & 1.6 & 1.74 & 4.1 & 21.6 & 3.7 & 15.1 & 0 \\
\hline MT-1 & 3.5 & $7.10^{-4}$ & 0.15 & - & - & - & - & - & 0 \\
\hline
\end{tabular}

SLD values assuming $\rho_{P N} \sim 0$. Then, $\rho_{P X}$ can be expressed as :

$$
\rho_{P X}=\frac{-\rho_{K N}+\sqrt{R_{2 N}} \rho_{K X}}{\sqrt{R_{N}}}
$$

Calculated $\rho_{P X}$ values are listed in Table 7 and displayed two different values. For BSP samples, a $600 \rho_{P X}$ values ranging from $4.3 .10^{10} \mathrm{~cm}^{-2}$ up to $5.10^{10} \mathrm{~cm}^{-2}$ are estimated. This value can be attributed to 601 either light condensed hydrocarbons with SLD values smaller than pentane SLD $\left(6.2 .10^{10} \mathrm{~cm}^{-2}\right)$, or to 602 a mixture of pores fulfilled by a fluid and empty pores. For the overmature MT1 sample, a value of 0 603 is found for the nanopores $(0.5 \mathrm{~nm})$ population and a value slightly negative for the mesopore $(3.5 \mathrm{~nm})$ 604 population. The agreement with both a meaningful (positive) $\rho_{P X}$ value and the best fit intensities 605 gives a null value for mesopores SLD. Hence, for the overmature sample, nano- and meso- pores in 
606 kerogen are considered as empty in full agreement with Sh0 and Sh1 values found with Rock-Eval 607 pyrolysis measurements.

608 From the prefactors $n\left(\rho_{P}-\rho_{K}\right)_{X, N}^{2}$ and the SLD values, the number density of pores $n$ were easily 609 assessed and their values are reported in Table 7. The nanopores volume fraction $\phi$ can be inferred 610 from their number density $n$ and their size distribution using $\phi=n 4 / 3 \pi<R^{3}>$, where $<R^{3}>$ is the

611 third moment of the size distribution that can be calculated analytically for the lognormal distribution.

612 Numerical values are reported in Table 7. They are in the range 1-4\% and rank roughly like the TOC 613 content.

614 Concerning the pyrite influence on SAXS data, calculated intensities for BSP-4 and MT-1 samples, 615 which exhibit the highest pyrite content (2.3 and $2.5 \% \mathrm{vol})$, display the higher discrepancy with 616 measured intensities in the $Q$ range around $0.1 \AA^{-1}$. This discrepancy is clearly ascribed to pyrite 617 content that gives an additional intensity contribution. If intensity modeling is still acceptable for these 618 samples, it is clear that for samples containing higher pyrite contents, the fitting procedure will give 619 meaningless parameters, especially for the mesopores SLD. Hopefully, the other estimated parameters 620 would stay unaffected by pyrite.

621

\section{DISCUSSION}

623 Source rocks is one of the most difficult material to characterize. Indeed, they are multiphase 624 systems (minerals, solid organic matter and pore space filled by various liquid or gaseous 625 hydrocarbons) and the relevant length scales extend from sub-nanometer for nanopores included in 626 kerogen up to few microns for minerals or kerogen domains. Moreover, they are natural materials with 627 inherent composition variability and laminated rocks where bedding could induce a structural 628 orientation leading to anisotropy of properties. Based on these considerations, sample preparation is 
629 one of the major concern when studying such materials. Complementary scattering techniques are

630 chosen here for their ability to probe the desired length scales. Herein, an innovative methodology is

631 proposed to overcome (i) composition variability, and (ii) loose of sample integrity and orientation

632 upon grinding. Thin blade samples allows to average several random X-ray scattering measurements

633 in a surface comparable to the section the neutron beam (a $5 \mathrm{~mm}$ diameter circular diaphragm). A

634 sample thickness of $\sim 200 \mu \mathrm{m}$, allow to get usable transmission for both radiation while avoiding

635 multiple scattering. Contrary to scattering measurements on powdered sample ${ }^{14,20,35,77}$ or on thin blade

636 section cut parallel to bedding ${ }^{10,23,27,28}$ that gives isotropic signal, the thin blades considered here are

637 cut normal to the bedding plane in order to get information on possible structural orientation. ${ }^{8,82}$

638 Finally, this sample preparation allow to compare X-ray and neutron scattering intensities obtained on

639 the same volume and in the same orientation.

640 Quantifying this orientation has to be taken into account when considering fluid flow properties for

641 transport issues or mechanical properties. Indeed, it is well known that bedding structures modify the

642 rock permeability to fluids according to the considered orientation, ${ }^{8,12,17,83}$ with values ranging from

$6431.10^{-19} \mathrm{~m}^{2}$ to $1.10^{-21} \mathrm{~m}^{2}$, for normal to bedding cut, and $1.10^{-21} \mathrm{~m}^{2}$ to $1.10^{-22} \mathrm{~m}^{2}$, for parallel to bedding

644 cut. In soil science, recent studies evidenced the importance of preferred clay orientation on the

645 diffusional properties of water. ${ }^{84}$ Here, order parameter vary from 0 (random orientation) up to $\sim 0.3$.

646 The random orientation is associated to the coarse grained texture of Montney sample whereas

647 significant values of order parameters are found for fine grained Barnett shales. This striking

648 difference could be the result of various size ratio between low dimensionality particles such as clays

649 or micas and other minerals. Indeed, it has been shown, on model systems of particles mixture

650 (platelets and spheres), that orientation upon sedimentation depend on the diameter ratio. ${ }^{85}$ Anisotropic

651 properties are also illustrated by the HS-GC experiment conducted on thin blade sections where the 
652 concentration of thermodesorbed species in the vapor is much larger for normal cut than for parallel 653 cut to the bedding (Supplementary Data).

654 The quantitative comparisons of X-ray and neutron scattering intensities are based on contrast factor 655 specific to each radiation. The detailed examination of scattering length densities evidence that source 656 rocks could be described for both radiation with three distinct contributions : minerals, kerogen and 657 pores. For overmature kerogens, the neutron scattering could be reduced to the frequently used two 658 phase system approximation, matrix and pores. ${ }^{8,10,14,20,23,27,28,35,39,79}$ This two phases model, based on 659 diluted polydispersed pores, is usually applied to retrieve the pore size distribution and the total 660 porosity. Here, considering three phases allow to broaden scattering techniques to low mature 661 kerogens and to X-ray measurements. A corresponding expression of scattering intensities based on 662 two main contributions is developed. The first one is related to the dispersion of kerogen domains in 663 the mineral matrix, which prevails at low $Q$ values, and turns out to be anisotropic. The second one 664 describes a diluted dispersion of nanopores in the kerogen, giving a dominant isotropic signal at large $665 Q$ values that remains moderate. We took advantage of anisotropy to consider the azimuthal direction 666 where the scattering at low $Q$ is reduced in order to better appreciate the contribution, at large $Q$ 667 values, of kerogen nanoporosity. The three phases model allows to fit both X-ray and neutron data 668 with the same geometric parameters which prove the selectivity of the model. Moreover, the intensity 669 ratio between X-ray and neutron prefactors for each contribution allow to retrieve valuable parameters 670 such as (i) the X-ray and neutron kerogen SLD as well as its mass density, both of them being 671 considered as a maturity index, (ii) the nanopore size distribution, the number density of nanopores 672 and their associated volume fraction, and (iii) the X-ray SLD of nanopores that gives a first 673 approximation on the nature of filling fluids. All these parameters are reachable thanks to quantitative 674 comparison of SANS and SAXS measurements, a strategy commonly applied to solve complex 
675 nanostructural order. ${ }^{86,87}$ The pyrite has not been taken into account for SAXS modeling and we show

676 that for pyrite content above $\sim 2.5 \mathrm{vol} \%$, the SLD of nanopores is suspicious rendering the nature of 677 filling fluid unclear.

678 This methodology has been applied to a series of source rocks with an increasing maturity according 679 to Rock-Eval pyrolysis measurements. For mature samples, the SAXS/SANS analysis show (i) a 680 kerogen mass density of $\sim 1.64 \mathrm{~g} . \mathrm{cm}^{-3}$ in good agreement with geochemical estimation (ii) a nanopore 681 size radius distribution centered on $0.5-0.7 \mathrm{~nm}$, in agreement with the literature, ${ }^{20,35,79,88}$ with $20 \%$ of 682 polydispersity and accounting for pore volume fractions of $\sim 0.01$ to 0.04 . When the volume fraction is 683 compared to the Rock-Eval pyrolysis TOC content ( 4.5 to $9 \% \mathrm{wt})$, the proportion of pores in 684 kerogen is about a fifth to a half of the kerogen domain. At such pore concentration, the assumption of 685 diluted pores could not always be valid and considering a structure factor $S(Q)$ in the intensities 686 modeling should be taken into account. As any peak in the high $Q$ region, relative to a short range pore 687 ordering, has been detected, a structure factor rather based on pore aggregates should be considered. It 688 would give additional information on nanopore connectivity relevant for future studies and (iii) an X689 ray nanopores SLD of $\sim 4$ to $5.10^{10} \mathrm{~cm}^{-2}$. These values can account for either condensed (liquid) light 690 hydrocarbons or a mixture of heavier condensed hydrocarbons and empty pores. For the overmature 691 sample, the kerogen mass density is higher $\left(1.74 \mathrm{~g} . \mathrm{cm}^{-3}\right)$ as expected, the pore size distribution is 692 bimodal with a mode close to the one of mature sample and an additional distribution of mesopores 693 (with a radius of $3.5 \mathrm{~nm}$ ) accounting for a small pore volume fraction of $\sim 0.1-0.2 \%$. Both porous 694 media are found to be empty in full agreement with almost null values of free hydrocarbons as 695 measured in the Sh0 and Sh1 values using Rock-Eval pyrolysis.

696 The developed methodology of sample preparation, measurement and data modeling allow to reach 697 several valuable parameters relevant for source rocks studies. Its application seems to give satisfactory 
698 results in comparison with already known parameters. The SAXS measurements could be improved

699 notably. By using shorter wavelength (e.g. molybdenum), transmission would be higher, the exposure

700 time lower and the fluorescence eliminated. If this wavelength is tuned finely around the absorption

701 edge of Fe (ASAXS), the scattering contribution of pyrite should be mitigated rendering the pore

702 content more accurate. As mentioned, data acquired with a better statistic would also allow to consider

703 a smaller azimuthal aperture and to better appreciate the moderate signal of nanopores.

704 Finally, this fine characterization of the porous media could be seen as a first step before the 705 introduction or the removal of various compounds, including hydrocarbons or $\mathrm{CO}_{2}$, from the pores 706 space. The proposed methodology, based on contrasts, would allow to probe the affinity of a fluid to 707 pores contained in kerogen and would provide information on the pore connectivity.

\section{5. CONCLUSION}

709 This study was performed to better characterize source rocks for transport or mechanical issues. For 710 that, a new methodology based on SAXS/SANS complementarity is developed. The sample 711 preparation, thin blade section cut normal to bedding, allow to compare directly the anisotropic X-ray 712 and neutron patterns. From 2D scattering analysis, an order parameter likely related to the preferential 713 orientation of lamellar minerals is inferred. It represents a valuable parameter that could be used for 714 mechanical or transport properties issues. At large $Q$ values, an additional isotropic scattering 715 contribution, ascribed to nanopores in kerogen, is evidenced and mostly apparent at specific azimuthal 716 angles. For these later, the 1D scattering profiles are modeled by two contributions related to three

717 distinct phases : minerals, kerogen and pores. These two contributions are weighted by prefactors that 718 are different for each radiation. The exploitation of both prefactor, together with the one of the 719 scattering model allow to retrieve valuables parameters such as a kerogen maturity index, number 720 density of nanopores leading to their size distribution and also their associated volume fraction. The 
721 latter being related to the kerogen maximum storage capacity for gaseous species or condensed fluids.

722 Moreover, X-ray pore space SLD gives some indications about the nature of filling fluids.

723 This methodology is tested on a series of source rocks of increasing maturities. The same set of

724 geometrical parameters allow to fit both X-ray and neutron data proving the selectivity of the model.

725 The kerogen maturity index is in agreement with the Rock-Eval pyrolysis maturity approximation. The

726 nanopore sizes and their associated volume fraction are in the range of, respectively, $0.5-0.7 \mathrm{~nm}$ and

727 0.01-0.04 for mature source rocks. They are likely filled either by light hydrocarbons, or a mixture of

728 heavy hydrocarbons and empty pores. For the overmature one, an additional pore size of $3.5 \mathrm{~nm}$,

729 accounting for a volume fraction of $\sim 0.2 \%$, is evidenced. For both population, pores appears empty in

730 full agreement with Rock-Eval pyrolysis measurements.

731 This new methodology proved to be efficient and open a new way to look quantitatively at 732 nanoporous kerogen phase and its in-situ evolution upon treatment such as emptying or filling it with 733 various fluids.

\section{ACKNOWLEDGEMENT}

737 The authors are grateful to IFP Energies Nouvelles and PHENIX laboratory for their financial and

738 scientific support. We thank E. Bemer (IFPEN) and W. Sassi (IFPEN) for providing the source rock

739 samples as part of GASH and MGH projects. We also thank M. Detrez for his technical support on

740 PA20 and the Laboratoire Léon Brillouin which provide SANS instrumentation and the financial 741 support for this experiment. We are grateful to P. Hayrault and F. Moreau for their help respectively 742 on HS-GC interpretation and FESEM experiment. All authors contributed to the discussion, the 743 writing and the review of this paper. 


\section{7. SUPPORTING INFORMATION}

746 SAXS measurements on different sample thickness $(100,140$ and $200 \mu \mathrm{m})$ are provided in 747 supplementary data as an illustration for no multiple scattering effects. Then, I(Q) as a function of

748 lamellar minerals content, for X-ray or neutron radiation, and as a function of TOC content (neutron

749 radiation) are provided. For the fitting procedure, data concerning pyrite modelization on SAXS data 750 and nanopores radius sensitivity, are displayed in supporting information. Chromatograms of HS-GC 751 measurements along source rocks lamination (normal or parallel cut to bedding) are also detailed.

754 1- Kuuskraa V. A.; Stevens S. H. and Moodhe, K. (2013) World Shale Gas and Shale Oil Resource 755 Assessment. EIA/ARI.

756 2- Godec M.L.; Jonsson H. and Basava-Reddi L. (2013) Potential Global Implications of Gas 757 Production from Shales and Coal for Geological CO2 Storage. In : Energy Procedia, vol. 37, p. 6656758 6666. DOI: 10.1016/j.egypro.2013.06.598.

759 3- IEA (2007). World Energy Outlook 2007: China and India Insights. In : IEA, Paris, ISBN: 978$760 \quad 92-64-02730-5$

761 4- IEA (2019), World Energy Outlook 2019, In : IEA, Paris https://www.iea.org/reports/world762 energy-outlook-2019 
763 5- Bennaceur K.; Gielen D.; Kerr T. and Tam C. (2008) $\mathrm{CO}_{2}$ capture and storage. A key carbon 764 abatement option. In : International Energy Agency : Organisation for Economic Co-operation and 765 Development. Paris (Energy technology analysis). ISBN : 978-92-64-04140-0

766 6- Zhao J.; Jin Z.; Hu Q.; Jin Z.; Barber T.J.; Zhang Y. and Bleuel M. (2017) Integrating SANS and 767 fluid-invasion methods to characterize pore structure of typical American shale oil reservoirs. In : 768 Nature communications, vol. 7. DOI: 10.1038/s41598-017-15362-0.

769 7- Radlinski A.P; Mastalerz M.; Hinde A.L; Hainbuchner M.; Rauch H.; Baron M.; Lin J.S.; Fan L. 770 and Thiyagarajan P. (2004) Application of SAXS and SANS in evaluation of porosity, pore size 771 distribution and surface area of coal. In : International Journal of Coal Geology, vol. 59, n 3-4, p. 772 245-271. DOI: 10.1016/j.coal.2004.03.002.

773 8- Gu X.; Cole D. R.; Rother G.; Mildner D.F.R. and Brantley S.L. (2015) Pores in Marcellus Shale: 774 A Neutron Scattering and FIB-SEM study. In : Energy \& Fuels, vol. 29, n 3, p. 1295-1308. DOI: $775 \quad 10.1021 /$ acs.energyfuels.5b00033

776 9- Ougier-Simonin A.; Renard F.; Boehm C. and Vidal-Gilbert S. (2016) Microfracturing and 777 Microporosity in Shales. In : Earth-Science Reviews, vol. 162, p. 198-226. DOI : $778 \quad 10.1016 /$ j.aerscirev.2016.09.006

779 10- Sun M.; Yu B.; Hu Q.; Yang R.; Zhang Y.; Li B.; Melnichenko Y.B. and Cheng G. (2018) Pore 780 structure characterization of organic-rich Niutitang shale from China. Small angle neutron scattering 781 (SANS) study. In : International Journal of Coal Geology, vol. 186, p. 115-125. DOI: 782 10.1016/j.coal.2017.12.006. 
783 11- Craddock P.R.; Bake K.D. and Pomerantz A.E. (2018) Chemical, Molecular, and 784 Microstructural Evolution of Kerogen during Thermal Maturation: Case study from the Woodford 785 Shale of Oklahoma. In : Energy \& Fuels, vol. 32, $\mathrm{n}^{\circ}$ 4, p. 4859-4872. DOI: 786 10.1021/acs.energyfuels. 8 b00189

787 12- Backeberg N. R.; Lacoviello F.; Rittner M.; Mitchell T. M.; Jones A.P.; Day R.; Wheller J.; 788 Shearing P.R.; Vermeesch P.and Striolo A. (2017) Quantifying the Anisotropy and Tortuosity of 789 Permeable Pathways in Clay-Rich Mudstones using Models based on X-ray Tomography. In : 790 Scientific Reports, vol. 7. DOI: 10.1038/s41598-017-14810-1.

791 13- Rouquerol J.; Avnir D.; Fairbridge C.W.; Everett D.H.; Haynes J.H.; Pernicone N.; Ramsay 792 J.D.F.; Sing K.S.W. and Unger K.K. (1994) Recommendations for the Characterization of Porous 793 Solids. International Union of Pure and Applied Chemistry. In : Pure \& Applied Chemistry, vol. 66, $\mathrm{n}^{\circ}$ $794 \quad 8$, p. 1739-1758.

795 14- Mastalerz M.; He L.; Melnichenko Y.B. and Rupp J.A. (2012) Porosity of Coal and Shale. 796 Insights from Gas Adsorption and SANS/USANS Techniques. In : Energy \& Fuels, vol. 26, n 8, p. 797 5109-5120. DOI: 10.1021/ef300735t.

798 15- Ruppert L.F.; Sakurovs R.; Blach T.P.; He L.; Melnichenko Y.B.; Mildner D.F.R. and Alcantar799 Lopez L. (2013) A USANS/SANS Study of the Accessibility of Pores in the Barnett Shale to Methane 800 and Water. In Energy \& Fuel, vol. 27, p. 722-779. DOI : 10.1021/ef301859s

801 16- Tissot B.P. and Welte D.H. (1984) Petroleum Formation and Occurence. Springer-Verlag.

802 17- Chalmers G.R.L.; Bustin R.M. and Power I.M. (2012) Characterization of gas shale pore 803 systems by porosimetry, pycnometry, surface area, and field emission scanning electron 
804 microscopy/transmission electron microscopy image analyses. Examples from the Barnett, Woodford, 805 Haynesville, Marcellus, and Doig units. In : AAPG Bulletin, vol. 96, nº 6, p. 1099-1119. DOI: $806 \quad 10.1306 / 10171111052$.

807 18- Melnichenko Y. B.; Radlinski A. P.; Mastalerz M.; Cheng G. and Rupp, J.A. (2009) 808 Characterization of the CO2 fluid adsorption in coal as a function of pressure using neutron scattering 809 techniques (SANS and USANS). In : International Journal of Coal Geology, vol. 77, n 1-2, p. 69-79. 810 DOI: 10.1016/j.coal.2008.09.017.

811 19- Pang Y.; Soliman M.Y.; Deng H. and Xie X. (2017) Experimental and analytical investigation of 812 adsorption effects on shale gas transport in organic nanopores. In : Fuel, vol. 199, p. 272-288. DOI: $813 \quad$ 10.1016/j.fuel.2017.02.072.

814 20- Bahadur J.; Radlinski A.P.; Melnichenko Y.B.; Mastalerz M. and Schimmelmann A. (2015) 815 Small-Angle and Ultrasmall-Angle Neutron Scattering (SANS/USANS) Study of New Albany Shale. 816 A Treatise on Microporosity. In : Energy \& Fuels, vol. 29, $\mathrm{n}^{\circ}$ 2, p. 567-576. DOI: $817 \quad 10.1021 /$ ef502211w.

818 21- King H.E.; Eberle A.P.R.; Walters C.C.; Kliewer C.E.; Ertas D. and Huynh C. (2015) Pore 819 Architecture and Connectivity in Gas Shale. In : Energy \& Fuels, vol. 29, n 3, p. 1375-1390. DOI: $820 \quad 10.1021 /$ ef502402e.

821 22- Eberle A.P.R.; King H.E.; Ravikovitch P.I.; Walters C.C.; Rother G. and Wesolowski, D.J. 822 (2016) Direct Measure of the Dense Methane Phase in Gas Shale Organic Porosity by Neutron 823 Scattering. In : Energy \& Fuels, vol. 30, n 11, p. 9022-9027. DOI: 10.1021/acs.energyfuels.6b01548. 
824 23- Sun M.; Yu B.; Hu Q.; Zhang Y.; Li B.; Yang R.; Melnichenko Y.B. and Cheng G. (2017) Pore 825 characteristics of Longmaxi shale gas reservoir in the Northwest of Guizhou, China. Investigations 826 using small-angle neutron scattering (SANS), helium pycnometry, and gas sorption isotherm. In : 827 International Journal of Coal Geology, vol. 171, p. 61-68. DOI: 10.1016/j.coal.2016.12.004.

828 24- Yang R.; He S.; Hu Q.; Sun M.; Hu D. and Yi J. (2017) Applying SANS technique to 829 characterize nano-scale pore structure of Longmaxi shale, Sichuan Basin (China). In : Fuel, vol. 197, 830 p. 91-99. DOI: 10.1016/j.fuel.2017.02.005.

831 25- Zhang R.; Liu S. and Wang Y. (2017) Fractal evolution under in situ pressure and sorption 832 conditions for coal and shale. In : Scientific reports, vol. 7, $\mathrm{n}^{\circ}$ 1, p. 8971. DOI: 10.1038/s41598-017$833 \quad 09324-9$.

834 26- Bodhisatwa H.; Suryendu D. and Sumit K. (2017) TOC calculation of organic matter rich 835 sediments using Rock-Eval pyrolysis: Critical consideration and insights. In : International Journal of 836 Coal Geology, vol. 169, p. 106-115.

837 27- Clarkson C. R.; Freeman M.; He L.; Agamalian, M.; Melnichenko, Y. B.; Mastalerz, M.; Bustin 838 R.M.; Radlinski A.P. and Blach T.P. (2012) Characterization of tight gas reservoir pore structure using 839 USANS/SANS and gas adsorption analysis. In : Fuel, vol. 95, p. 371-385. DOI: $840 \quad$ 10.1016/j.fuel.2011.12.010.

841 28- Clarkson C.R.; Solano N.; Bustin R.M.; Bustin A.M.M.; Chalmers G.R.L.; He, L.; Melnichenko 842 Y.B.; Radlinski A.P. and Blach T.P. (2013) Pore structure characterization of North American shale 843 gas reservoirs using USANS/SANS, gas adsorption, and mercury intrusion. In : Fuel, vol. 103, p. 606844 616. DOI: 10.1016/j.fuel.2012.06.119. 
29- Han H.; Cao Y.; Chen S.; Lu J.; Huang C.; Zhu H.; Zhan P. and Gao Y. (2016) Influence of 846 particle size on gas-adsorption experiments of shales. An example from a Longmaxi Shale sample 847 from the Sichuan Basin, China. In : Fuel, vol. 186, p. 750-757. DOI: 10.1016/j.fuel.2016.09.018.

848 30- Li P.; Jiang Z.; Zheng M.; Bi H. and Chen L. (2016) Estimation of shale gas adsorption capacity 849 of the Longmaxi Formation in the Upper Yangtze Platform, China. In : Journal of Natural Gas Science 850 and Engineering, vol. 34, p. 1034-1043. DOI: 10.1016/j.jngse.2016.07.052.

851 31- Romero-Sarmiento M.F.; Pillot D.; Letort G.; Lamoureux-Var V.; Beaumont V.; Huc A.Y. and 852 Garcia B. (2016) New Rock-Eval Method for Characterization of Unconventional Shale Resource 853 Systems. In : Oil \& Gas Science and Technology - Revue d'IFP Energies nouvelles, vol. 71, n 3, p. 854 37. DOI: $10.2516 /$ ogst/2015007.

855 32- Wang P.; Jiang Z.; Yin L.; Chen L.; Li Z.; Zhang C.; Li T. and Huang P. (2017) Lithofacies 856 classification and its effect on pore structure of the Cambrian marine shale in the Upper Yangtze 857 Platform, South China. Evidence from FE-SEM and gas adsorption analysis. In : Journal of Petroleum 858 Science and Engineering, vol. 156, p. 307-321. DOI: 10.1016/j.petrol.2017.06.011.

859 33- Melnichenko Y.B. (2016) Small-Angle Scattering from Confined and Interfacial Fluids. Cham : 860 Springer International Publishing.

861 34- Anovitz L M.; Cole D. R. (2015) Characterization and Analysis of Porosity and Pore Structures. 862 In : Reviews in Mineralogy and Geochemistry, vol. 80, $\mathrm{n}^{\circ}$ 1, p. 61-164. DOI: $863 \quad 10.2138 / \mathrm{rmg} .2015 .80 .04$

864 35- Bahadur J.; Melnichenko Y. B.; Mastalerz M.; Furmann A. and Clarkson C.R. (2014) 865 Hierarchical Pore Morphology of Cretaceous Shale. A Small-Angle Neutron Scattering and 
866 Ultrasmall-Angle Neutron Scattering Study. In : Energy \& Fuels, vol. 28, n 10, p. 6336-6344. DOI: $86710.1021 /$ ef501832k.

868 36- Chalmers G.R.L. and Bustin R.M. (2015) Porosity and Pore Size Distribution of Deeply-Buried 869 Fine-Grained Rocks: Influence of Diagenetic and Metamorphic Processes on Shale Reservoir Quality 870 and Exploration. In : Journal of Unconventional Oil and Gas Resources, vol. 12, p. 134-142. DOI: $871 \quad$ 10.1016/j.juogr.2015.09.005

872 37- Clarkson C.R.; Haghshenas B.; Ghanizadeh A.; Qanbari F.; Williams-Kovacs J.D.; Riazi, N.; 873 Debuhr C. and Deglint H.J. (2016) Nanopores to megafractures. Current challenges and methods for 874 shale gas reservoir and hydraulic fracture characterization. In : Journal of Natural Gas Science and 875 Engineering, vol. 31, p. 612-657. DOI: 10.1016/j.jngse.2016.01.041.

876 38- Liu S.; Zhang R.; Karpyn Z.T.; Yoon H. and Dewers T. (2019) Investigation of accessible pore 877 structure evolution under pressurization and adsorption for coal and shale using small-angle neutron 878 scattering. In : Energy \& Fuels. DOI: 10.1021/acs.energyfuels.8b03672.

879 39- Radlinski A.P.; Boreham C.J.; Lindner P.; Randl O.; Wignall G.D.; Hinde A. and Hope J.M. 880 (2000) Small Angle Neutron Scattering Signature of Oil Generation in Artificially and Naturally 881 Matured Hydrocarbon Source Rocks. In : Organic Geochemistry, vol. 31, p. 1-14. DOI: $882 \quad 10.1016 / \mathrm{S} 0146-6380(99) 00128-\mathrm{X}$

883 40- Kang S.M.; Fathi E.; Ambrose R.J.; Akkutlu I.Y. and Sigal R.F. (2011) Carbon Dioxide Storage 884 Capacity of Organic-Rich Shales. In : SPE Journal, vol. 16, p. 842-855. DOI: 10.2118/134583-PA. 
41- Bodhisatwa H.; Wood D.A.; Vishal V. and Singh A.K. (2018) Pore Characteristics of Distinct

886 Thermally Mature Shales : Influence of Particle Size on Low-Pressure $\mathrm{CO}_{2}$ and $\mathrm{N}_{2}$ Adsorption. In :

887 Energy and Fuels, vol. 32, p. 8175-8186. DOI: 10.1021/acs.energyfuels.8b01439.

888 42- Davudov D.; Moghanloo R.G. and Lan Y. (2018) Evaluation of Accessible Porosity Using 889 Mercury Injection Capillary Pressure Data in Shale Samples. In : Energy and Fuels, vol. 32, p. 4682890 4694. DOI: 10.1021/acs.energyfuels.7b03930.

891 43- Habina I.; Radzik N.; Topór T. and Krzyżak A.T. (2017) Insight Into Oil and Gas-Shales 892 Compounds Signatures in Low Field $1 \mathrm{H}$ NMR and its Application in Porosity Evaluation. In : 893 Microporous and Mesoporous Materials, vol. 252, p. 37-49. DOI: 10.1016/j.micromeso.2017.05.054.

894 44- Shaoqing T.; Yanhui D.; Qian Z.; Derek E.; Shimin L. (2017) Quantitative Analysis of 895 Nanopore Structural Characteristics of Lower Paleozoic Shale, Chongqing (Southwestern China): 896 Combining FIB-SEM and NMR Cryoporometry. In : Energy and Fuels, vol. 31, p. 13317-13328. DOI: 897 10.1021/acs.energyfuels.7b02391

898 45- Xinhe S.; Xiongqi P.; Hui L. and Xue Z. (2017) Fractal Analysis of Pore Network in Tight Gas 899 Sandstones Using NMR Method: A Case Study from the Ordos Basin, China. In : Energy and Fuels, 900 vol. 10, $\mathrm{n}^{\circ}$ 31. DOI: 10.1021/acs.energyfuels.7b01007.

901 46- Fleury M.; Fabre R. and Webber J.B.W. (2015) Comparison of Pore Size Distribution by NMR 902 Relaxation and Nmr Cryoporometry in Shales. In : Society of Core Analysis.

903 47- Korb J.P.; Nicot B.; Louis-Joseph A.; Bubici S. and Ferrante G.(2014) Dynamics and 904 Wettability of Oil and Water in Oil Shales. In : The Journal of Physical Chemistry C, vol. 118, $\mathrm{n}^{\circ} 40$, 905 p. 23212-23218. DOI: $10.1021 /$ jp508659e. 
906 48- Radlinski A. P.; Hinde A. L.; Rauch H.; Hainbuchner M.; Baron M.; Mastalerz M.; Ioannidis M. 907 and Thiyagarajan P. (2005) The microstructure of rocks and small-angle and ultra-small-angle neutron 908 scattering: the coming of age of a new technique. In : Geophysical Research Abstracts, vol. 7.

909 49- Lee S.; Fischer T.B.; Stokes M.R.; Klingler R.J.; Ilavsky J.; McCarty D.K.; Wigand M.O.;

910 Derkowski A. and Winans R.E., (2014) Dehydration Effect on Pore Size, Porosity, and Fractal 911 Parameters of Shale Rocks: USAXS Study. In : Energy and Fuels, vol. 28, p. 6772-6779. DOI: $91210.1021 /$ ef501427d.

913 50- Leu L.; Georgiadis A.; Blunt M.J.; Busch A.; Bertier P.; Schweinar K.; Liebi M.; Menzel A. and 914 Ott H. (2016) Multiscale Description of Shale Pore Systems by Scanning SAXS and WAXS 915 Microscopy. In : Energy and Fuels, vol. 30, p.10282-10297. DOI: 10.1021/acs.energyfuels.6b02256.

916 51- Hall P.L.; Mildner D.F.R. and Borst R.L. (1986) Small-angle scattering studies of the pore 917 spaces of shaly rocks. In : Journal of Geophysical Research, vol. 91, $\mathrm{n}^{\circ}$ B2, p. 2183. DOI: $918 \quad 10.1029 / J B 091 i B 02 p 02183$.

919 52- Pillot D.; Letort G.; Romero-Sarmiento M.F.; Lamoureux-Var V.; Beaumont V. and Garcia B. 920 (2014) Method of Assessing at Least one Petroleum Characteristic of a Rock Sample. Patent $921 \quad 14 / 55.009$.

922 53- Chen S.; Han Y.; Fu C.; Zhang H.; Zhu Y. and Zuo Z. (2016) Micro and nano-size pores of clay 923 minerals in shale reservoirs. Implication for the accumulation of shale gas. In : Sedimentary Geology, 924 vol. 342, p. 180-190. DOI: 10.1016/j.sedgeo.2016.06.022. 
925 54- Espitalié J.; Deroo G. and Marquis F. (1986) La Pyrolyse Rock-Eval et ses Applications : 926 Troisième Partie. In: Revue de l'Institut Français du Pétrole, Vol. 41, p. 73-89. DOI : $927 \quad 10.2516 /$ osgt : 1986003.

928 55- Liao L.; Wang Y.; Chen C.; Shi S. and Deng R. (2018) Kinetic study of marine and lacustrine 929 shale grains using Rock-Eval pyrolysis. Implications to hydrocarbon generation, retention and 930 expulsion. In : Marine and Petroleum Geology, vol. 89, p. 164-173. DOI: 931 10.1016/j.marpetgeo.2017.01.009.

932 56- Ghanizadeh A.; Bhowmik S.; Haeri-Ardakani O.; Sanei H. and Clarkson C.R. (2015)a A 933 Comparison of Shale Permeability Coefficients Derived using Multiple Non-Steady-State 934 Measurement Techniques: Examples frome the Devernay Formation, Alberta (Canada). In : Fuel, vol. 935 140, p. 371-387. DOI:10.1016/j.fuel.2014.09.073.

936 57- Ghanizadeh A.; Clarkson C.R.; Aquino S.; Haeri-Ardakani O. and Sanei H. (2015)b 937 Petrophysical and Geomechanical Characteristics of Candaian Tight Oil and Liquid-Rich Gas 938 Reservoirs: I. Pore Network and Permeability Characterization. In : Fuel, vol. 153, p. 664-681. DOI: $939 \quad 10.1016 /$ j.fuel.2015.03.020.

940 58- Bernard S.; Horsfield B.; Schulz H.M.; Schreiber A.; Wirth R.; Anh Vu T.T.; Perssen F.; 941 Könitzer S.; Volk H.; Sherwood N. and Fuentes D. (2010) Multi-Scale Detection of Organic and 942 Inorganic Signatures Provides Insights into Gas Shale Properties and Evolution. In : Chemie der Erde, 943 vol. 70, p. 119-133. DOI: 10.1016/j.chemer.2010.05.005.

944 59- Bernard S.; Wirth R.; Schreiber A.; Schulz H.M. and Horsfield B. (2012) Formation of 945 Nanoporous Pyrobitumen Residues During Maturation of the Barnett Shale (Fort Worth Basin). In : 946 Internation Journal of Coal Geology, vol. 103, p. 3-11. DOI : 10.1016/j.coal.2012.04.010. 
947 60- Jayne R.S.; Wu H. and Pollyea R.M. (2019) Geologic $\mathrm{CO}_{2}$ Sequestration and Permeability 948 Uncertainty in a Highly Heterogeneous Reservoir. In : International Journal of Greenhouse Gas 949 Control, vol. 83, p. 128-139. DOI: 10.1016/j.ijggc.02.001.

950 61- Medina C.R.; Mastalerz M. and Rupp J.A. (2018) Pore System Characterization of Cambrian951 Ordovician Carbonates Using a New Mercury Porosimetry-Based Petrofacies Classification System: 952 Application to Carbon Sequestration Reservoirs. In : Greenhouse Gases Science and Technology, vol. 953 8, p. 932-953. DOI : 10.1002/ghg

954 62- Rietveld H.M. A Profile Refinement Method for Nuclear and Magnetic Structure. Journal of 955 Applied Crystallography, 1969, vol. 2, p. 65-71. DOI: 10.1107/S0021889869006558

956 63- Loucks R.G. and Ruppel S.C. (2007) Mississippian Barnett Shale. Lithofacies and depositional 957 setting of a deep-water shale-gas succession in the Fort Worth Basin, Texas. In : AAPG Bulletin, vol. $95891, \mathrm{n}^{\circ} 4$, p. 579-601. DOI: 10.1306/11020606059.

959 64- Davidson P.; Petermann D. and Levelut A.M. (1995) The Measurement of Nematic Order 960 Parameter by X-ray Scattering Reconsidered. In : Journal de Physique II, vol. 5, p. 113-131. DOI: $961 \quad 10.1051 / j p 2: 1995117$.

962 65- Paineau E.; Antonova K.; Baravian C.; Bihannic I.; Davidson P.; Dozov I.; Impéror-Clerc M.; 963 Levitz P.; Madsen A.; Meneau F. and Michot L.J. (2009) Liquid-Crystalline Nematic Phase in 964 Aqueous Suspensions of a Disk-Shaped Natural Beidellite Clay. In : Journal of Physical Chemistry B, 965 vol. 113, p. 15858-15869. DOI: 10.1021/jp908326y

966 66- Paineau E.; Krapf M.E.M.; Amara M.S.; Matskova N.V.; Dozov I.; Rouzière S.; Thill A.; 967 Launois P. and Davidson P. (2016) A Liquid-Crystallin Hexagonal Columnar Phase in Highly-Dilute 
968 Suspensions of Imogolite Nanotubes. In : Nature Communications, vol. 7. DOI : $96910.1038 /$ ncomms 10271

970 67- Suzzoni A.; Barré L.; Kohler E.; Levitz P.; Michot L.J. and M’Hamdi J. (2018) Interactions

971 between Kaolinte Clay and AOT. In : Colloids and Surfaces A: Physicochemical and Engineering 972 Aspects, vol 556, p. 309-315. DOI: 10.1016/j.colsurfa.2018.07.049

973 68- Maier V.W. and Saupe A. (1959) Theorie der Nematischen Kristallinflüssigen Phase. Teil I. In : 974 Z. Naturforschg, vol. 14a, p. 882-889.

975 69- Maier V.W. and Saupe A. (1960) Eine Einfache Molekular-Statistische Theorie der Nematischen 976 Kristallinflüssigen Phase. Teil II. In : Z. Naturforschg, vol. 15a, p. 287-292.

977 70- Ilgen A.G.; Heath J.E.; Akkutlu I.Y.; Bryndzia L.T.; Cole D.R.; Kharaka Y.K.; Kneafsey T.J.; 978 Miliken K.L.; Pyrak-Nolte L.J. and Suarez-Rivera R. (2017) Shales at all scales. Exploring coupled 979 processes in mudrocks. In : Earth-Science Reviews, vol. 166, p. 132-152. DOI: $980 \quad 10.1016 /$ j.earscirev.2016.12.013.

981 71- Thomas J.J.; Valenza J.J.; Craddock P.R.; Bake K.D. and Pomerantz A.E. (2014) The neutron 982 scattering length density of Kerogen and coal as determined by $\mathrm{CH} 3 \mathrm{OH} / \mathrm{CD} 3 \mathrm{OH}$ exchange. In : Fuel, 983 vol. 117, p. 801-808. DOI: 10.1016/j.fuel.2013.09.075.

984 72- Espinat D. (1990) Applications des techniques de diffusion de la lumière, des rayons X et des 985 neutrons à l'étude des systèmes colloïdaux. ISBN : 2-7108-0617-7

986 73- Arthur M.A. and Cole D.R. (2014) Unconventional Hydrocarbon Resources. Prospects and 987 Problems. In : Elements, vol. 10, p. 257-264. DOI: 10.2113/gselements.10.4.257 
988 74- Bazilevskaya E.; Rother G.; Mildner D.F.R.; Pavich M.; Cole D. and Bhatt M.P. (2015) How 989 Oxidation and Dissolution in Diabase and Granite Control Porosity during Weathering. In : Soil 990 Science Society of American Journal, vol. 79, p. 55. DOI: 10.2136/sssaj2014.04.0135

991 75- Bale H.D. and Schmidt P.W., (1984) Small-Angle X-Ray-Scattering Investigation of 992 Submicroscopic Porosity with Fractal Properties. In : Physical Review Letters, vol. 53. DOI: $993 \quad 10.1103 /$ PhysRevLett.53.596.

994 76- Broseta, D.; Barré, L.; Vizika, O.; Shahidzadeh, N.; Guilbaud, J. P.; Lyonnard, S. (2001) 995 Capillary Condensation in a Fractal Porous Medium. In : Physical Review Letters, vol. 86, p. 5313996 5316. DOI: 10.1103/PhysRevLett.86.5313

997 77- Radlinski A.P. (2006) Small-Angle Neutron Scattering and the Microstructure of Rocks. In 998 Reviews in Mineralogy \& Geochemistry, vol. 63, p. 363-397. DOI : 10.2138/rmg.2006.63.14

999 78-Schmidt P.W. (1982) Interpretation of Small-Angle Scattering Curves Proportional to a Negative 1000 Power of the Scattering Vector. In : Journal of Applied Crystallography, vol. 15, p. 567-569. DOI: $1001 \quad 10.1107 / \mathrm{S} 002188988201259 \mathrm{X}$.

1002 79- Bahadur J.; Ruppert L.F.; Pipich V.; Sakurovs R. and Melnichenko Y.B. (2018) Porosity of the 1003 Marcellus Shale. A contrast matching small-angle neutron scattering study. In : International Journal 1004 of Coal Geology, vol. 188, p. 156-164. DOI: 10.1016/j.coal.2018.02.002.

1005 80- Blach T.; Radlinski A.P.; Edwards D.S.; Boreham C.J.; Rehm C.; Campo L. and Gilbert E.P. 1006 (2018) Fingerprint of hydrocarbon generation in the southern Georgina Basin, Australia, revealed by 1007 small angle neutron scattering. In : International Journal of Coal Geology, vol. 186, p. 135-144. DOI: $1008 \quad$ 10.1016/j.coal.2017.10.013. 
1009 81- Bressler I.; Kohlbrecher J. and Thünemann A. F. (2015) SASfit: a Tool for Small-Angle 1010 Scattering Data Analysis using a Library of Analytical Expressions. In : Journal of Applied 1011 Crystallography, vol. 48, p. 1587-1598. DOI: 10.1107/S1600576715016544.

1012 82- Liu S. and Zhang R. (2020) Anisotropic Pore Structure of Shale and Gas Injection-Induced 1013 Nanopore Alteration : A Small-Angle Neutron Scattering Study. In : Internation Journal of Coal 1014 Geology, vol. 219. DOI: 10.1016/j.coal.2020.103384.

1015 83- Kwon O.; Kronenberg A.K.; Gangi A.F.; Johnson B. and Herbert B.E. (2004) Permeability of 1016 Illite-Bearing shale : 1. Anisotropy and Effects of Clay Content and Loading. In : Journal of 1017 Geophysical Research, vol. 109, B10205. DOI: 10.1029/2004JB003052.

1018 84- Dabat T.; Porion P.; Hubert F.; Paineau E.; Dazas B.; Grégoire B.; Tertre E.; Delville A. and 1019 Ferrage E. (2020) Influence of Preferred Orientation of Clay Particles on the Diffusion of Water in 1020 Kaolinite Porous Media at Constant Porosity. In : Applied Clay Science, vol. 184. DOI: $1021 \quad 10.1016 /$ j.clay.2019.105354

1022 85- Sui J. (2019) Stratification in the Dynamics of Sedimenting Colloidal Platelet-Sphere Mixture. 1023 In : Soft Matter, vol. 23., p. 4714-4722 DOI: 10.1039/C9SM00485H

1024 86- Forny-Le-Follotec A.; Glatter O.; Pezron I.; Barré L.; Noik C.; Dalmazzone C. and Metlas1025 Komunjer L. (2012) Characterization of Micelles of Small Triblock Copolymer by Small-Angle 1026 Scattering. In : Macromolecules, vol. 45, p. 2874-2881. DOI: 10.1021/ma201610n

1027 87- Eyssautier J.; Levitz P.; Espinat D.; Jestin J.; Gummel J.; Grillo I. and Barré L. (2011) Insight 1028 into Asphaltene Nanoaggragate Structure Inferred by Small Angle Neutron and X-ray Scattering. In :

1029 The Journal of Physical Chemistry B, vol. 115, p. 6827-6837. DOI: 10.1021/jp111468d 
1030 88- Bousige C.; Matei Ghimbeu C.; Vix-Guteri C.; Pomerantz A.E.; Suleimenova A.; Vaughan G.;

1031 Garbarino G.; Feygenson M.; Wildgruber C.; Ulm F.J.; Pellenq R.J.M. and Coasne B. (2016) Realistic

1032 Molecular Model of Kerogen's Nanostructure. In : Nature materials. DOI: 10.1038/NMAT4541 